This document is confidential and is proprietary to the American Chemical Society and its authors. Do not copy or disclose without written permission. If you have received this item in error, notify the sender and delete all copies.

\title{
Molecularly Imprinted Polymer Colloids Synthesized by Miniemulsion Polymerization for Recognition and Separation of Nonylphenol
}

\begin{tabular}{|r|l|}
\hline Journal: & ACS Applied Polymer Materials \\
\hline Manuscript ID & ap-2020-005609.R2 \\
\hline Manuscript Type: & Article \\
\hline Dute Submitted by the & $\mathrm{n} / \mathrm{a}$ \\
\hline Complete List of Authors: & $\begin{array}{l}\text { Decompte, Emile; IPREM } \\
\text { Lobaz, Volodymyr; Akademie ved Ceske republiky Ustav } \\
\text { makromolekularni Chemie, Supramolecular polymer systems } \\
\text { Monperrus, Mathilde; Institut Pluridisciplinaire de Recherche sur } \\
\text { I'Environnement et les Matériaux, Laboratoire de Chimie Analytique Bio- } \\
\text { inorganique et Environnement } \\
\text { Deniau, Elise; University of Pau \& Pays Adour, IPREM } \\
\text { Save, Maud; Equipe de physique et Chimie des Polymeres, CNRS - } \\
\text { Université de Pau et des Pays de I'Adour }\end{array}$ \\
\hline
\end{tabular}

\section{SCHOLARONE" Manuscripts}




\title{
Molecularly Imprinted Polymer Colloids Synthesized by
}

\section{Miniemulsion Polymerization for Recognition and Separation of}

\author{
Nonylphenol
}

\author{
Emile Decompte, ${ }^{\dagger}$ Volodymyr Lobaz, ${ }^{\ddagger}$ Mathilde Monperrus, ${ }^{\dagger}$ Elise Deniau, ${ }^{\dagger}$ Maud Save ${ }^{* \dagger}$ \\ ${ }^{\dagger}$ CNRS, University Pau \& Pays Adour, E2S UPPA, Institut des Sciences Analytiques et de \\ Physico-Chimie pour l'Environnement et les Matériaux, IPREM, UMR5254, 64000, PAU, \\ France. \\ ¥ Institute of Macromolecular Chemistry AS CR, Heyrovsky Sq. 1888/2, 16206 Prague 6, \\ Czech Republic. \\ Mail: maud.save@univ-pau.fr
}

Table of Contents (TOC)/Abstract Graphic

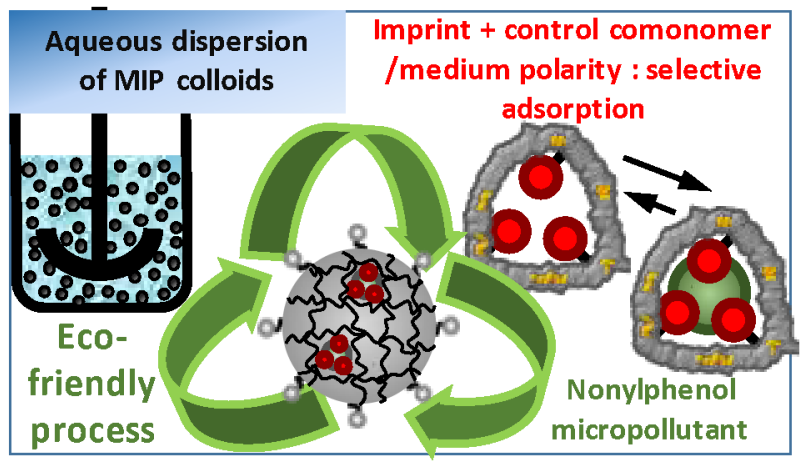


Abstract

Submicronic molecularly imprinted polymer (MIP) colloids were synthesized by polymerization in aqueous dispersed media for selective separation of nonylphenol (NP) organic pollutant. Miniemulsion polymerization process based on ultra-sheared monomer droplets allowed dispersion of the hydrophobic organic pollutant template to produce waterdispersible colloidal MIP. Structural parameters of the crosslinked polymer particles were tuned during the synthesis to achieve the best compromise between good specificity of imprinted polymer (MIP) sorbent compared to non-imprinted polymer (NIP) (ie imprinting factor $(\alpha)$ ), sufficient level of adsorption capacity $(Q)$ and selectivity of MIP towards the organic pollutant. For that purpose, the polymerization takes place in the organic monomer droplets containing nonylphenol (NP), $N$-vinylcaprolactam (VCL), different co-monomers (vinyl acetate (VAc), vinyl benzoate (VB) or 2-ethylhexanoic acid vinyl ester (VeoVa-EH)) and various contents of divinyl adipate (DVA) crosslinker. Tuning the level of hydrophobic interactions, either by the hydrophobicity of the co-monomer (VeoVa-EH $>\mathrm{VB}>\mathrm{VAc}$ ) or by the polarity of the hydroalcoholic mixture used for interfacial adsorption, achieved imprinting factors above unity. The binding of NP follows a monolayer Langmuir adsorption and the present MIPs selectively recognize NP compared to phenol. Isothermal titration calorimetry (ITC) measurements corroborated both specificity $\left(\Delta \mathrm{H}_{\mathrm{MIP}}>\Delta \mathrm{H}_{\mathrm{NIP}}\right)$ and selectivity with very low values of binding enthalpy of phenol, $p$-cresol and 1-octanol compared to NP.

Keywords: polymerization aqueous dispersed media, microgel, selective adsorbent, organic micropollutant, $\operatorname{poly}(N$-vinyl caprolactam) 


\section{Introduction}

Molecularly imprinted polymers (MIP) are biomimetic synthetic receptors promoting selective adsorption thanks to a recognition favoured by the 3-dimensional binding site created by the target molecule used as template for MIP synthesis. ${ }^{1-3}$ Templates can be organic molecules such as pollutants, pesticides, pharmaceuticals or biomolecules like peptide, proteins, biomarkers. Increasing attention to the presence of emerging organic pollutants that persist in wastewaters, surface waters and ground waters has been rationalized by the 2000/60/EC, 2008/105/EC and 2013/39/EU directives from European Commission establishing a list priority substances in the field of water policy. Herein, we focused our attention on nonylphenol (NP) and its isomers as organic micropollutant. The term micropollutant refers to a substance of anthropogenic origin present in natural waters at low concentrations, below several micrograms per liter. ${ }^{4,5}$ Nonylphenol ethoxylates are surfactants widely used for industrial, commercial and household applications thanks to their good performances and cost efficiency. ${ }^{6}$ The degradation of nonylphenol ethoxylates by stepwise loss of ethoxy groups produces ethoxylated congeners, carboxylated products, and nonylphenols (NPs). NPs are classified as endocrine disruptors due to their ability to mimic natural estrogens such as $17 \beta$-estradiol. ${ }^{7,8}$. The concentration of NP in water effluents is usually low ${ }^{9}$ as this lipophilic contaminant is adsorbed by sludge particles and can accumulate in soils and sediments. Pre-concentration methods through solid phase extraction (SPE) were developed to achieve detectable concentrations of hydrophobic compounds by using reduced volume of solvent compared to liquid-liquid phase extraction. One of the major challenges when dealing with traces of emerging pollutants such as NP is to carry out reliable analytical measurements for sensing. It is thus of particular interest to impart the specificity of binding sites of MIPs to SPE materials to achieve molecular recognition of pollutants. $^{10,11}$ The synthesis of MIPs is based on the creation of specific cavities in a crosslinked polymeric matrix. ${ }^{12}$ The imprint molecule can be covalently grafted onto a 
polymerizable vinylic group but a cleavage procedure is required after the polymerization step. Since the early work of Mosbach et al., ${ }^{13}$ the complex between imprint molecule and functional monomers has been mostly based on non-covalent interactions such as hydrogen bonding or ionic interaction, ${ }^{13,14}$ which widened the range of available monomers and template. ${ }^{1,2,15,16}$ It is important to note that after the template molecule is extracted, the resulting MIP contains imprinting cavities with shape, size and functionality complementary to those of the templates. ${ }^{1 \text {, }}$ 2, 12 However, preparing MIPs for specific recognition in aqueous matrix, particularly for lipophilic molecules like NP, still faces challenges. ${ }^{17}$

MIPs were mostly prepared by bulk polymerization but the mechanical grinding and sieving steps tend to decrease the MIP performances. ${ }^{18}$ In order to overcome this issue, spherical MIP particles with uniform sizes were synthesized by precipitation polymerization ${ }^{18-20}$ or nonaqueous miniemulsion polymerization ${ }^{21}$ both carried out in organic solvent allowing an efficient templating by hydrogen bonding. There is an increasing need to develop green processes by reducing the use of solvents while producing water-compatible MIP particles for efficient detection of organic molecules present in a water phase. Moreover, increasing the exchange surface with decreasing particle size can induce a better separation efficiency of MIP. ${ }^{22}$ Recently, a green synthesis of water-compatible fluorescent MIP nanoparticles was claimed but the harmful dimethylformamide solvent was required for both copolymer synthesis and self-assembly prior to nanoparticle formation at low solids content of $0.5 \mathrm{wt}-\% .{ }^{23}$ In that context, polymerization in aqueous dispersed media processes are of particular interest. ${ }^{24}$ Among these processes, miniemulsion polymerization ${ }^{25}$ is especially relevant to address several challenges for MIP synthesis. It simultaneously offers the opportunity to create the H-bonding monomer/template complex directly in the initial hydrophobic monomer droplets and to endup with submicronic water-compatible stable particles dispersed in a continuous aqueous phase. While precipitation polymerization in organic solvent is mostly carried out at low solids content 
$(<2 \mathrm{wt}-\%)$ to avoid macrogelation, miniemulsion polymerization can be implemented at higher solids content (up to 10-30 wt- $\%$ ) thanks to the polymerization and crosslinking confined in the monomer droplets. Miniemulsion polymerization was successfully carried out to synthesize MIPs targeting specific recognition for drugs, ${ }^{26-29}$ proteins, ${ }^{30-34}$ and pollutants ${ }^{35}$ or as nanoreactor in catalyzed multicomponent reactions. ${ }^{36}$ On the other hand, few studies have been devoted to the design of MIPs for the specific and selective adsorption of nonylphenol (NP) as organic contaminant. ${ }^{11,37-51}$ Their syntheses were performed by precipitation polymerization or surface imprinting in organic solvents such as toluene, acetonitrile or dimethylformamide. Poly( $N$-vinylcaprolactam) (PVCL) is a non-toxic biocompatible polymer ${ }^{52}$ able to promote hydrogen bonding with hydroxyl or carboxylic acid groups. ${ }^{53-56}$ PVCL has been previously involved in MIP synthesis for recognition of gemcitabine ${ }^{57}$ or sumatriptan succinate templates ${ }^{58}$ but none of these MIPs were designed as colloidal particles dispersed in water. Since the early work of Zuber et al. ${ }^{59}$ about PVCL particles synthesized by miniemulsion polymerization involving toluene as co-solvent, only two recent works have investigated the design of PVCLbased particles by miniemulsion polymerization. ${ }^{60}$, 61 The present work investigates polymerization in aqueous dispersed media as a green process to synthesize submicronic MIP colloids for the selective recognition of the hydrophobic NP pollutant in a water-based medium (Scheme 1). 

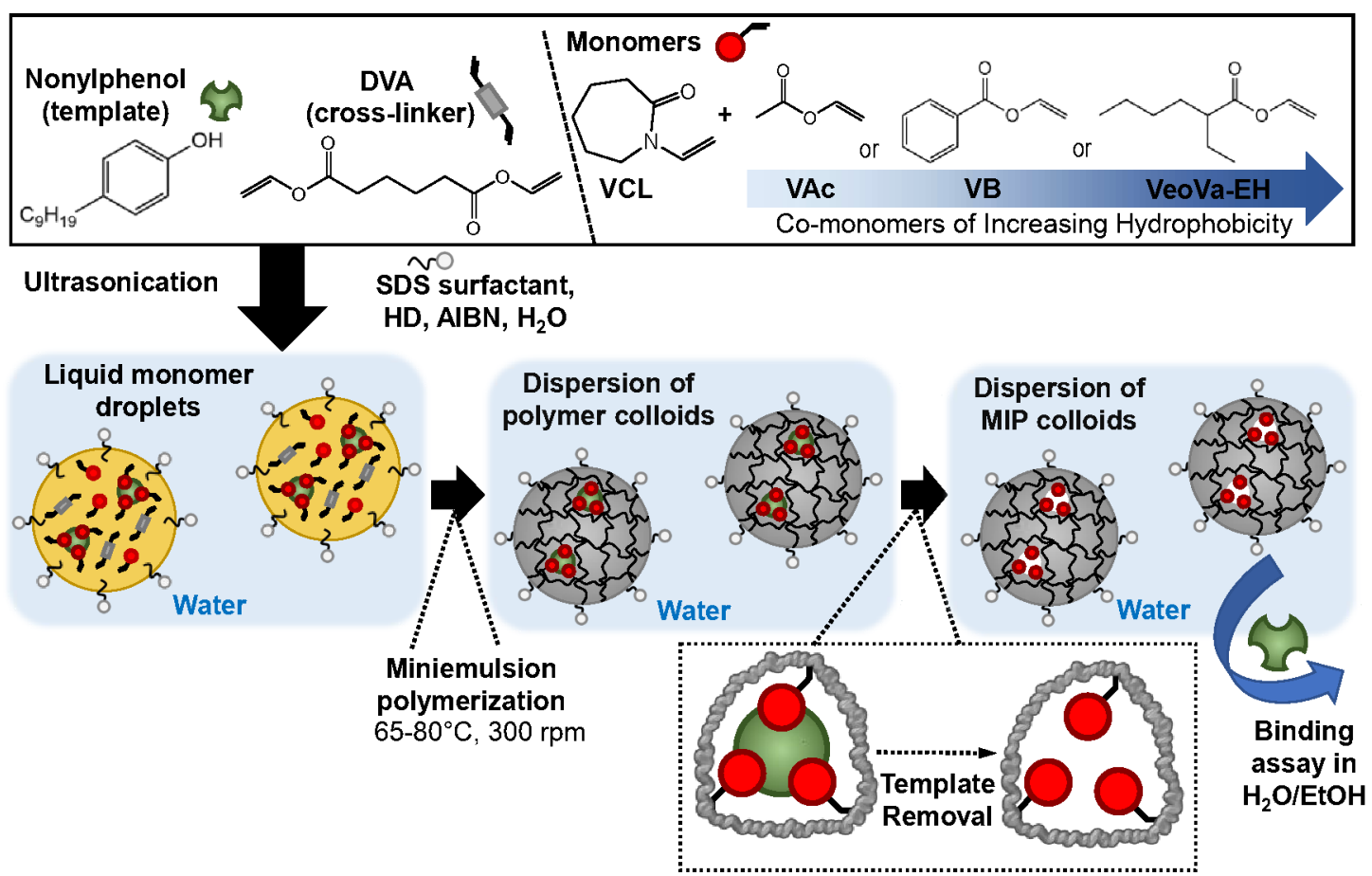

Scheme 1. Synthetic Strategy for Aqueous Dispersion of Colloidal MIP For Nonylphenol Selective Binding $(\mathrm{VAc}=$ vinyl acetate, $\mathrm{VB}=$ vinyl benzoate, $\mathrm{VeoVA}-\mathrm{EH}=$ 2-ethylhexanoic vinyl ester).

Herein, PVCL-based MIP colloids are synthesized by miniemulsion polymerization starting from ultra-sheared monomer droplets containing VCL, divinyl adipate (DVA) crosslinker and a liquid vinyl ester co-monomer, so that loaded NP can pre-organize by non-covalent intermolecular interactions such as $\mathrm{H}$-bonding or hydrophobic interactions with the monomers. This work explores the experimental conditions for miniemulsion polymerization to achieve high monomer conversion and excellent colloidal stability in the presence of NP pollutant. The amphiphilic balance of MIP particles was tuned by copolymerizing VCL, DVA with a series of comonomers of increasing hydrophobicity (vinyl acetate (VAc), vinyl benzoate (VB) or 2ethylhexanoic acid vinyl ester (VeoVA-EH)) in order to target the optimum binding efficiency of NP with MIP/NIP particles. Concomitantly, the impact of the solvent polarity on the adsorption capacity and specificity is investigated in various water/ethanol mixtures. Isothermal titration calorimetry (ITC) provides reliable information on the supramolecular binding 
interactions of nonylphenol with MIP and NIP particles. Finally, the selectivity of MIPs for nonylphenol versus phenol, $p$-cresol and 1-octanol is highlighted.

\section{Experimental section}

\section{Materials}

Vinyl acetate (VAc, Sigma Aldrich, 99\%+) was mixed with inhibitor remover resin (Sigma Aldrich, $0.1 \mathrm{~g}$ of inhibitor remover for hydroquinone and monomethyl ether hydroquinone in $50 \mathrm{~mL}$ of VAc) for 30 minutes in an ice bath prior to be filtered and used for polymerization. $N$-vinylcaprolactam (VCL, Sigma Aldrich, 98\%), vinyl benzoate (VB, Sigma Aldrich, $\geq 99 \%$ ), azobis(isobutyronitrile) (AIBN, Sigma Aldrich, 98\%), 1,3,5-trioxane (Sigma Aldrich, $\geq 99 \%$ ), hexadecane (HD, Sigma Aldrich, 99\%), sodium $n$-dodecyl sulfate (SDS, ABCR, 99\%), sodium hydrogenocarbonate $\left(\mathrm{NaHCO}_{3}, \mathrm{VWR}\right.$, Rectapur, 99\%), divinyl adipate (DVA, TCI Chemicals, $>99 \%$, nonylphenol (NP, Technical Grade, Sigma Aldrich), N,Obis(trimethylsilyl)trifluoroacetamide with $1 \%$ of trimethylchlorosilane (BSTFA $+1 \%$ TMCS, Sylon BFT, 99:1, Supelco), ethanol absolute (VWR, Normapur, $\geq 99.8 \%$ ), ethyl acetate (VWR, Rectapur, $\geq 99 \%$ ), dichloromethane (VWR, Normapur, $\geq 99.5 \%$ ) were used as received. VeoVATM EH monomer, a vinyl ester of 2-ethyl hexanoic acid, was kindly supplied by Momentive (now Synthomer) and used as received. phenol (Sigma Aldrich, $\geq 99 \%$ ), p-cresol (Sigma Aldrich, 99\%), 1-octanol (Sigma Aldrich, $\geq 99 \%$ ).

\section{Preparation of the imprinted (MIP) and non-imprinted (NIP) colloids}

All the colloids were synthesized by miniemulsion polymerization of VCL as functional monomer, DVA as crosslinker and with or without a liquid co-monomer (VAc, VeOVA or VB). Surfactant (SDS) and hydrophobic agent (HD) were kept constant at 2.25 and 2 wt.- $\%$ based on monomers and crosslinker and the final targeted solids content of the aqueous dispersion of polymer colloids (latex) was set at 10 wt.-\% (Table S1 and Table S2). Miniemulsion copolymerization of VAc and VCL was carried out at $65^{\circ} \mathrm{C}$ (boiling point VAc $=72{ }^{\circ} \mathrm{C}$ ) while syntheses of DVA-VCL-VB and DVA-VCL-VeOVA-EH latexes were performed at $80^{\circ} \mathrm{C}$. Nonylphenol was added in the monomer phase for MIP synthesis while NIPs are free of nonylphenol. In the example of MIP-DVA $15-\mathrm{VCL}_{42}-\mathrm{VAc}_{43}$ synthesis, the organic phase was prepared as follows: the template molecule nonylphenol $(0.871 \mathrm{~g})$, the functional monomer $N$ vinylcaprolactam (2.202 g), the co-monomer vinyl acetate (1.362 g) and the crosslinker divinyl adipate $(1.129 \mathrm{~g})$ were mixed with the hydrophobic agent hexadecane $(0.094 \mathrm{~g})$ and an NMR 
standard 1,3,5-trioxane $(0.336 \mathrm{~g})$. The mixture was sonicated in an ultrasonic bath for $10 \mathrm{~min}$ at room temperature. Next, the initiator $\operatorname{AIBN}(0.245 \mathrm{~g})$ was added and the mixture was briefly shaken at room temperature to solubilize the initiator. The aqueous phase was prepared separately according to the following procedure: $\operatorname{SDS}(0.106 \mathrm{~g})$ and $\mathrm{NaHCO}_{3}$ buffer $(0.053 \mathrm{~g})$ were mixed with $45 \mathrm{~mL}$ of deionized water. The mixture was then magnetically stirred for 20 minutes. Next, the two phases were mixed in order to form an emulsion which was stirred for 15 minutes in an ice bath. The resulting solution was sonicated with an ultrasonic probe for 6 min in an ice bath to prevent any thermal initiation, to obtain the droplet miniemulsion. The mixture was then put into a two-necked round bottom flask equipped with a stirring bar. The reactor was sealed prior to be degassed with nitrogen during $20 \mathrm{~min}$ in an ice bath. Next, the reactor immersed an oil bath heated at $65^{\circ} \mathrm{C}$ and the mixture was mechanically stirred at 300 rpm for $6 \mathrm{~h}$. To remove any unreacted monomers, surfactant or initiator, the resulting colloids were purified by dialysis in water (Spectra/Por, cut-off $3.5 \mathrm{kDa}$ ). The colloidal MIP was then recovered and a dry extract was used to measure the solid content after purification. The reproducibility of MIP-VAc $17-\mathrm{VCL}_{17}-\mathrm{DVA}_{66}$ synthesis was shown in Figure S1.

\section{Procedure for extraction of the template molecule after synthesis of MIP particles.}

The dialyzed colloidal particles have been first centrifuged at 20,000 rpm (48,324 g-force) for 20 min at $15^{\circ} \mathrm{C}$ on a Beckman AvantiJ30 (JA 25-50 rotor). A second centrifugation cycle was carried out in a mixture of ethanol/acetic acid $(9 / 1 \mathrm{v} / \mathrm{v})$ to disrupt the H-bonding and promote the NP release. For measurements of the amount of extracted NP by UV-visible spectroscopy, the colloids were redispersed in ethanol and several centrifugation cycles at 20,000 rpm $(48,324$ g-force) have been carried out for $20 \mathrm{~min}$ at $15^{\circ} \mathrm{C}$ until the remaining NP concentration could not be quantified in the supernatant (Figure S2). The particles were dispersed by Vortex stirring for 3 min between each centrifugation, followed by sonication in an ultrasonic bath at room temperature for $5 \mathrm{~min}$ and a further stirring step of $3 \mathrm{~min}$. In the case of adsorption of NP carried out in pure water phase, the range of NP concentration to be detected is far lower due to the low limit concentration of water solubility of NP $\left([\mathrm{NP}]_{\mathrm{H} 20}<2.2 \times 10^{-5} \mathrm{~mol}^{-\mathrm{L}^{-1}}\right){ }^{6,62} \mathrm{Such}$ concentrations are below the proper quantification limit of UV-visible spectrophotometer so a switch to GC-MS detection provided more reliable measurements of concentrations of extracted and further adsorbed NP. For that purpose, additional centrifugation cycles of MIP and NIP particles in ethyl acetate was required to end up with residual NP concentrations in the supernatant as low as tens of $\mu \mathrm{g} \cdot \mathrm{L}^{-1}$ (1- $100 \mathrm{ppb)} \mathrm{(Table} \mathrm{S4,} \mathrm{Figure} \mathrm{S2).} \mathrm{Note} \mathrm{that} \mathrm{a}$ derivatization of NP is required prior GC-MS to overcome its low volatility. The additional 
centrifugation cycles were performed in ethyl acetate since it was proved to be the most suitable solvent to implement the trimethylsilylation derivatization of alkylphenols using BSTFA. ${ }^{63}$ All the cleaned imprinted colloids were freeze-dried under vacuum overnight. The nonimprinted particles were also washed to check that the concentration of nonylphenol was below the limit of detection for each detection method.

\section{Adsorption of pollutant onto MIP and NIP particles.}

For the measurement of the adsorption capacity in water/ethanol mixtures, $50 \mathrm{mg}$ of freezedried MIP (or NIP) were introduced in the centrifugation tubes to be dispersed with $5 \mathrm{~mL}$ of hydroalcoholic NP solutions $\left([\mathrm{NP}]_{0}=0.5 \mathrm{mmol} . \mathrm{L}^{-1}=110 \mathrm{mg} . \mathrm{L}^{-1} ;[\mathrm{MIP}]_{0}=[\mathrm{NIP}]_{0}=10\right.$ g.L$\left.{ }^{1}\right)$. The mixture has been magnetically stirred at $400 \mathrm{rpm}$ for 4 hours at room temperature prior to be centrifuged at $15,000 \mathrm{rpm}(27,216 \mathrm{~g}$-force $)$ at $15^{\circ} \mathrm{C}$ for $20 \mathrm{~min}$. The maximum absorbance of NP at $278 \mathrm{~nm}$ was selected to measure its concentration in the supernatant. By reproducing 6 similar experiments, the error on the absorbance is $1.4 \%$. The molar extinction coefficient of $\mathrm{NP}$ at $278 \mathrm{~nm}\left(\varepsilon_{278 \mathrm{~nm}}\left(\mathrm{~L} \cdot \mathrm{mol}^{-1} \cdot \mathrm{cm}^{-1}\right)\right)$ was determined in the different hydroalcoholic mixtures to calculate the NP concentration from Beer-Lambert law (Figure S4). The adsorption capacity $Q$ (mg. $\left.\mathrm{g}^{-1}\right)$ is the weight of adsorbed nonylphenol by weight of MIP or NIP colloids (Eq 1).

$Q=\left(C_{0}-C_{e q}\right) \cdot \frac{V_{0}}{m}$

$\mathrm{Eq} 1$

Where $C_{0}\left(\mathrm{mg} . \mathrm{L}^{-1}\right)$ is the initial concentration of NP, $C_{\text {eq }}\left(\mathrm{mg} . \mathrm{L}^{-1}\right)$ is the equilibrium concentration of NP measured in the supernatant, $V_{0}(\mathrm{~L})$ is the volume of the solution and $m(\mathrm{~g})$ is the initial weight of the colloids (MIP or NIP). The adsorption yield (\%) is calculated according to Eq 2 .

$\% A d s=100 \cdot \frac{\left(C_{0}-C_{e q}\right)}{C_{0}}$

Eq 2The specific adsorption corresponds to the ratio between the adsorption capacity of MIP $Q_{\text {MIP }}\left(\mathrm{mg} . \mathrm{g}^{-1}\right)$ over the one of NIP homologue $Q_{\mathrm{NIP}}\left(\mathrm{mg}_{\mathrm{g}} \mathrm{g}^{-1}\right)$. This property is defined as the imprinting factor $(\alpha)$ calculated according to $\mathrm{Eq} 3$.

$\alpha=\frac{Q_{M I P}}{Q_{N I P}}$

Eq 3

The selective adsorption is expressed by the selectivity coefficient $(k, \mathrm{Eq} 4)$ calculated from the distribution coefficient $\left(K_{\mathrm{d}}\right.$, Eq 5$)$ of the target analyte (NP) and interfering analyte (Phenol). 
The relative selectivity factor $(\beta, \mathrm{Eq} 6)$ can be calculated to compare the selectivity coefficient between NIP and MIP. ${ }^{64,65}$

$k=\frac{K_{d}(N P)}{K_{d}(\text { Phenol })}$

Eq 4

$K_{d}=\frac{Q}{C_{e q}}$

Eq 5

$\beta=\frac{k_{M I P}}{k_{N I P}}$

Eq 6For the measurement of the adsorption capacity of NP onto MIP/NIP in water in the absence of ethanol, $10 \mathrm{mg}$ of dried MIP (or NIP) were dispersed in centrifuge tubes with $1 \mathrm{~mL}$ $\left([\mathrm{MIP}]_{0}=[\mathrm{NIP}]_{0}=10 \mathrm{~g} \cdot \mathrm{L}^{-1}\right)$ of NP in water $\left([\mathrm{NP}]_{0}=4.5 \mu \mathrm{mol} \cdot \mathrm{L}^{-1}=1 \mathrm{mg} \cdot \mathrm{L}^{-1}=1 \mathrm{ppm}\right)$. This dispersion was favoured by 3 minutes vortex, 3 minutes ultrasounds and 1 minute vortex shaking. The mixture has been gently stirred at $60 \mathrm{rpm}$ for 4 hours at room temperature prior to be centrifuged on an Eppendorf MiniSpin ${ }^{\circledR}$ centrifuge (rotor F-45-12-11) at 13,400 rpm $(12,100 \mathrm{~g}$-force $)$ and room temperature for $20 \mathrm{~min}$. The NP present in the aqueous supernatant was extracted with dichloromethane to accurately measure it concentration by GC-MS in the absence of colloidal particles. The dichloromethane extracted $92 \%$ of NP from water phase (see protocol of extraction and derivatization for GC-MS in SI).

The NP adsorption isotherms of NP onto selected MIP were measured in 50/50 (v/v) water/ethanol mixture at room temperature. The adsorption capacity $(Q$, see Eq 1) was measured at different initial concentrations of NP $\left(C_{0}=0.5,1,2,5\right.$ and $20 \mathrm{mmol} \cdot \mathrm{L}^{-1}$, ie from 0.1 to 4.4 g.L $\mathrm{L}^{-1}$ ) by using $10 \mathrm{mg}$ of MIP particles at a concentration of $2 \mathrm{~g} . \mathrm{L}^{-1}$.

\section{Desorption experiments}

Prior to any desorption experiments, the concentration of adsorbed nonylphenol $\left(C_{\mathrm{ads}}=C_{0}-\right.$ $C_{\text {eq }}$ ) was first measured in 50/50 (v/v) water/ethanol mixture with $C_{0}=0.5 \mathrm{mmol}^{-\mathrm{L}^{-1}}$ (see protocol in the adsorption part). Different desorption temperatures of 30,40 and $50^{\circ} \mathrm{C}$ were investigated as well as the influence of the ultrasonication on desorption. The colloids recovered by centrifugation after the adsorption step were dispersed in $5 \mathrm{~mL}$ of pure ethanol with magnetic stirring at $400 \mathrm{rpm}$ for $10 \mathrm{~min}$ in a pre-heated oil bath at the corresponding temperature. In order to investigate the effect of ultrasound, the colloids were shaken in an ultrasonic bath for $10 \mathrm{~min}$ to be compared to a simple shaking at room temperature. Then, the colloids were centrifuged 
at $20000 \mathrm{rpm}(48,324 \mathrm{~g}$-force $)$ for $20 \mathrm{~min}$ at $15^{\circ} \mathrm{C}$ and the concentration of desorbed $\mathrm{NP}\left(C_{\mathrm{des}}\right)$ in the supernatant was measured by UV spectroscopy. The desorption yield was determined from $\mathrm{Eq} 7$.

$\%$ Des $=\frac{C_{\text {des }} \times V_{\text {des }}}{\left(C_{0} \times V_{0}\right)-\left(C_{e q} \times V_{e q}\right)}$

Eq 7

Refer to Eq 2 for $C_{0}\left(\mathrm{mg} . \mathrm{L}^{-1}\right), V_{0}(\mathrm{~L})$ and $C_{e q}\left(\mathrm{mg} . \mathrm{L}^{-1}\right)$. The other terms correspond to the volume of the centrifugation supernatant after adsorption step $\left(V_{e q}\right)$, the volume $\left(V_{\text {des }}\right)$ and NP concentration $\left(C_{d e s}\right)$ of the centrifugation supernatant measured after the desorption step.

\section{Characterization methods.}

Nuclear Magnetic Resonance (NMR) Spectroscopy. Proton nuclear magnetic resonance spectroscopy $\left({ }^{1} \mathrm{H}\right.$ NMR) spectra were recorded on a Bruker $400 \mathrm{MHz}$ spectrometer at $25{ }^{\circ} \mathrm{C}$. For the MIP and NIP syntheses, the overall conversion of vinylic compounds (monomer and crosslinker) was calculated from ${ }^{1} \mathrm{H}$ NMR spectra of the crude samples in DMSO- $d_{6}$ according to Eq 8 .

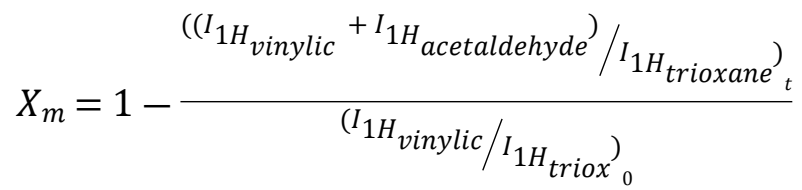

Eq 8

$I_{1 \mathrm{H}_{\text {trioxane }}}$ corresponds to the integral of 1,3,5-trioxane $(5.1 \mathrm{ppm}, 6 \mathrm{H})$ used as internal standard, and $I_{1 \mathrm{H}_{\text {vinylic }}}$ corresponds to the integral of the vinylic protons of VCL, DVA and either VAc, VB or VeoVA at $7.2-7.4 \mathrm{ppm}$. $I_{1 \mathrm{H}_{\text {acetaldehyde }}}(9.6 \mathrm{ppm}, 1 \mathrm{H})$ corresponds to the integral of the proton of the acetaldehyde produced by the hydrolysis of the VCL (Figure S5, Figure S6, Figure S7). ${ }^{66}$ The hydrolysis yield $\left(r_{\mathrm{Hy}}\right)$ are reported in Table S1.

Dynamic Light Scattering (DLS). The final average hydrodynamic diameters $\left(D_{\mathrm{h}}\right)$ of the MIP and NIP colloids were measured by dynamic light scattering using a Zetasizer Nano ZS instrument (Malvern Instruments). A He-Ne $4.0 \mathrm{~mW}$ power laser was used, operating at a wavelength of $633 \mathrm{~nm}$. Measurements were carried out at a solids content of $0.005 \mathrm{wt} \%(0.05$ g. $\left.\mathrm{L}^{-1}\right)$ at $25^{\circ} \mathrm{C}$. Before each scan, the sample was maintained at the set temperature for $5 \mathrm{~min} .{ }^{67}$ The hydrodynamic diameters of the initial monomer droplets were measured without any dilution step, at $10 \mathrm{wt} .-\%$ of solid content $\left(100\right.$ g.L $\left.\mathrm{L}^{-1}\right)$.

Ultraviolet-Visible (UV-Vis) Spectroscopy. UV-Vis analyses were performed using a Shimadzu Spectrophotometer model UV-2450 in quartz cells of $1 \mathrm{~cm}$ width. 
Gas Chromatography coupled to Mass Spectrometry (GC-MS). Chromatographic analyses were performed using a GC Model 7890A (Agilent Technologies) fitted with a split/splitless injector and a DB-5MS capillary column (cross-linked $5 \%$ diphenyl/95 \% dimethyl siloxane, $30 \mathrm{~m} \times 0.25 \mathrm{~mm} \times$ i.d. $0.25 \mu \mathrm{m}$ coating) from Agilent J\&W Scientific. The GC was coupled to an inert quadrupole mass spectrometric detector with triple axis detector, Model 5975C (Agilent Technologies) with electron impact (EI) ionization. ${ }^{68}$ GC-MS was used to further monitor low concentrations of NP.

Fourier Transform Infra-red Spectroscopy (FTIR). NIP colloids were analyzed by FTIR on a Nicolet IS50 de ThermoFischer Scientific equipment. Analyses were carried out on the powder in attenuated total reflection mode (ATR).

Isothermal Titration Calorimetry (ITC). ITC experiments were performed with a Microcal iTC200 apparatus (Malvern) using the following protocol. The NP was dissolved in ethanol/water $50 / 50(\mathrm{v} / \mathrm{v})$ to target a concentration of $20 \mathrm{mM}$ and microgels were dispersed in ethanol/water $50 / 50(\mathrm{v} / \mathrm{v})$ at concentration of $5 \mathrm{~g} . \mathrm{L}^{-1}$. The NP solution $(40 \mu \mathrm{L}$ of injectant $)$ was poured in the syringe and the microgel solution was placed in the cell. MilliQ water at $\mathrm{pH}$ 6-7 was used for most experiments. Aqueous solutions at pH 3.0 and $\mathrm{pH} 10.7$ were also prepared for experiments comparative experiments. The titration was achieved at $25^{\circ} \mathrm{C}$ with 19 injections of $2 \mu \mathrm{l}$ each, with an initial injection of $0.4 \mu \mathrm{l}$ to minimize the impact of equilibration artefacts and volume error due to the presence of residual liquid on the syringe. The system was equilibrated at stirring for 60 seconds before the first injection. Each injection was performed at fixed time intervals of $150 \mathrm{sec}$. The resulting curves were fitted using Origin software with the one set of sites model considering the interactions between binded ligand and all sites are identical. Both binding constant $(\mathrm{K})$ and enthalpy of the binding process $(\Delta \mathrm{H})$ are calculated from the fit of integrated heat absorbed or liberated over time $\left(\mathrm{kcal}^{\mathrm{mol}} \mathrm{m}^{-1}\right)$ of injectant as a function of the molar ratio of the ligand/binding site . Thus, the Gibbs free energy $(\Delta \mathrm{G})$ and the entropy $(\Delta \mathrm{S})$ are calculated from $\mathrm{Eq} 9$.

$\Delta G=-R T \ln K=\Delta H-T \Delta S$

Eq 9

Titration curves of the solute (NP or 1-octanol or $p$-cresol or phenol) added into the Ethanol/water 50/50 solvent (ie. absence of MIP) were carried out as background to take into account dilution effects in the titration curves. The measured heat of the dilution of the solute was subtracted from the overall heat of the adsorption of the solute on MIP or NIP particles prior to fitting. 
Transmission electron microscopy (TEM). TEM analyses of polymer particles were performed on a JEOL JEM2010 operating at $200 \mathrm{kV}$.

\section{Results and discussion}

The first goal was to achieve stable submicronic MIP particles of homogeneous diameters with high monomer conversion. For that purpose, miniemulsion polymerization of VCL, VAc and DVA carried out at $65^{\circ} \mathrm{C}$ was first optimized in the absence of NP by using different buffer and initiator concentrations. Experimental conditions, results and colloidal features are reported in SI (Table S1, Figure S8, Figure S9, Figure S10). Scaling down the droplet size was succeeded by ultra-shearing the initial monomer emulsion stabilized by sodium $n$-dodecyl sulfate (SDS) surfactant and adding hexadecane (HD) as hydrophobic agent to reduce the monomer diffusion through the water phase by the Ostwald ripening. ${ }^{25}$ DVA was chosen as crosslinker for its vinyl ester structure close to the one of vinyl ester comonomers used in the presence work. A close reactivity in copolymerization is expected to promote a more homogeneous polymer network and better locking of cavity. We previously showed very close reactivity ratio of vinyl acetate and $N$-vinylcaprolactam in radical copolymerization. ${ }^{69}$ The most suitable experimental parameters to synthesize well-defined NIPs colloids at $10 \mathrm{wt}-\%$ of solids are as follows: $2.2 \mathrm{wt}-$ $\%$ of SDS surfactant, 2.0 wt- $\%$ of HD as hydrophobe agent and 2.0 mol- $\%$ of $\mathrm{NaHCO}_{3}$ based on monomers and crosslinker. The optimized $\mathrm{NaHCO}_{3}$ content corresponds to 4.0 mol- $\%$ of $\mathrm{NaHCO}_{3}$ based on VCL monomer, which will be taken as reference for next experiments varying the fraction of crosslinker. TEM images confirmed the well-defined spherical shape of the NIP colloids in a submicronic range (Figure 1). 


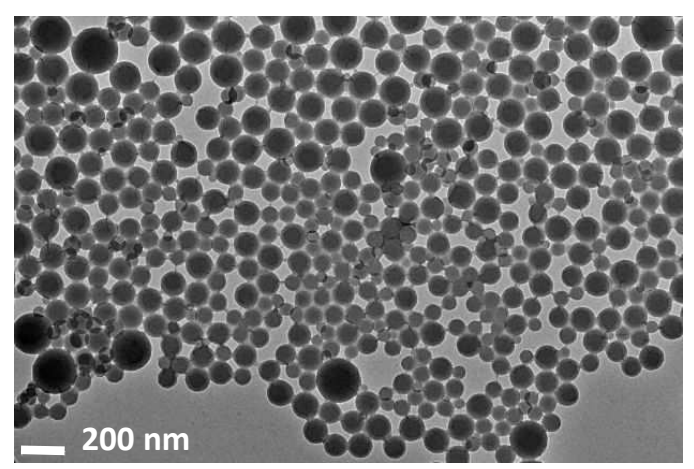

Figure 1. TEM pictures of NIP-DVA $33-\mathrm{VCL}_{33}-\mathrm{VAc}_{34}$ colloids (scale bar $200 \mathrm{~nm}$ ).

The synthesis of colloidal MIPs by miniemulsion polymerization was then performed in the presence of 25 mol-\% of nonylphenol (NP) versus the H-bonding VCL monomer. For such colloidal MIP synthesis, the concentration of AIBN initiator was investigated to overcome the inhibiting effect of NP, which was expected as the phenoxyl radicals formed from phenolic compounds are known as radical scavengers. ${ }^{70}$ The different results are detailed and discussed in SI (see Table S1, Figures S8, S9, S10). As a conclusion, while only 0.1 mol-\% of AIBN produces stable monodisperse NIP-DVA-VCL-VAc colloids up to high monomer conversion, 4 mol- $\%$ of AIBN based on monomers and crosslinker was required for the MIP synthesis. The nucleation time was sufficiently lowered to produce stable monodisperse MIP particles with hydrodynamic diameter $\left(D_{\mathrm{h}}\right)$ in the range of the initial monomer droplets $(180-195 \mathrm{~nm})$, which confirms a monomer droplet nucleation. The colloids were also characterized by DLS (Table S1, Figures S11 to S14 in SI). Monomodal diameter distributions and polydispersity index below 0.1 (Table 1) were characteristic of narrow particle size distribution.

\section{Synthesis of colloidal MIP and NIP particles with different hydrophobic co-monomers and various crosslinker ratios}

In a first series, MIPs and NIPs were synthesized by using three different co-monomers with varying chemical structure and hydrophobicity, ie methyl, benzyl and branched alkyl side 
groups (VAc, VB and VeoVA-EH) (Scheme 1). The monomer conversion was complete within 6 hours of miniemulsion polymerization, which implies that the average composition of the final copolymer should be close to the initial comonomer composition. FTIR ATR analyses of a series of colloids synthesized from the different comonomers, showed difference in spectra according to the nature of the comonomer (VAc, VeoVA, VB) (Figure S26). The absorbance band at $1630 \mathrm{~cm}^{-1}$ characteristic of the amide group of PVCL is systematically observed together with an ester band at $1725 \mathrm{~cm}^{-1}$ corresponding to both DVA crosslinker and vinyl ester comonomer. For instance, the additional band of aromatic carbon displayed at $710 \mathrm{~cm}^{-1}$ in NIP$\mathrm{DVA}_{33}-\mathrm{VCL}_{34}-\mathrm{VB}_{33}$ is a signature of the presence of aromatic VB comonomer (Figure S26). The hydrodynamic diameters of these colloidal MIPs and NIPs synthesized at 33 mol.- $\%$ of crosslinker ranged from 160 to $180 \mathrm{~nm}$ with an average polydispersity (PDI) below 0.1 which is characteristic of monodisperse colloids. The nature of the co-monomer does not significantly impacts the colloidal features as the hydrodynamic diameter and PDI are in a similar range (Table 1). The presence of nonylphenol neither significantly influenced the colloidal features as monomodal particle size distributions with $D_{\mathrm{h}}$ in a similar range for MIPs and NIPs were observed (Table 1 and Table S1 and Figure S13 in SI). Only MIP-DVA $66-\mathrm{VCL}_{17}-\mathrm{VeoVA}_{17}$ and MIP-DVA $66^{-} \mathrm{VCL}_{33}$ colloids exhibited slightly higher $D_{\mathrm{h}}$ compared to NIP. A longer nucleation period like in the presence of NP is mostly associated with decreasing the number of particles. Note that miniemulsion polymerization proceeds in the absence of aggregates or coagulum and the initial diameter of the monomer droplets were close to the final diameter of the colloids as expected for a droplet nucleation (Figure S12 in SI). It can also be noted that MIPs and NIPs were stable over months (Table S3 in ESI). 
Table 1. Experimental conditions for the synthesis of a series of MIPs and NIPs by miniemulsion polymerization at $10 \mathrm{wt}-\%$ of solids content. ${ }^{\mathrm{a}}$

\begin{tabular}{|c|c|c|c|c|c|c|c|c|}
\hline Sample $^{b}$ & co-M & $\begin{array}{c}\text { DVA }^{b} \\
(\%)\end{array}$ & $\begin{array}{c}C^{b} \\
(\%)\end{array}$ & $\begin{array}{c}\mathbf{c o}^{\mathbf{b}} \\
(\%)\end{array}$ & $\frac{[\mathrm{NP}]_{0}}{[\mathrm{VCL}]_{0}}$ & $\begin{array}{l}X_{m}^{c} \\
(\%)\end{array}$ & $\begin{array}{l}D_{\mathrm{h}}^{\mathrm{d}} \\
(\mathrm{nm})\end{array}$ & PDI $^{\mathbf{d}}$ \\
\hline NIP-DVA $32-V_{32}$-VeoVA 36 & VeoVA & 32 & 32 & 36 & - & 96 & 165 & 0.08 \\
\hline $\mathrm{MIP}-\mathrm{DVA}_{34}-\mathrm{VCL}_{33}-\mathrm{VeoVA}_{33}$ & VeoVA & 34 & 33 & 33 & 0.25 & $98^{\mathrm{e}}$ & 161 & 0.13 \\
\hline NIP-DVA $33-\mathrm{VCL}_{34}-\mathrm{VB}_{33}$ & VB & 33 & 34 & 33 & - & 97 & 143 & 0.06 \\
\hline $\mathrm{MIP}-\mathrm{DVA}_{33}-\mathrm{VCL}_{34}-\mathrm{VB}_{33}$ & VB & 33 & 33 & 34 & 0.26 & $98^{\mathrm{e}}$ & 181 & 0.13 \\
\hline $\mathrm{NIP}_{-\mathrm{DVA}}{ }_{6}-\mathrm{VCL}_{47}-\mathrm{VAc}_{47}$ & VAc & 6 & 47 & 47 & - & 95 & 173 & 0.07 \\
\hline $\mathrm{NIP} \mathrm{DVA} \mathrm{A}_{15}-\mathrm{VCL}_{42}-\mathrm{VAc}_{43}$ & VAc & 15 & 42 & 43 & - & 98 & 166 & 0.08 \\
\hline NIP-DVA $33-\mathrm{VCL}_{33}-\mathrm{VAc}_{34}$ & VAc & 33 & 33 & 34 & - & 98 & 163 & 0.07 \\
\hline $\mathrm{NIP}^{-D V A}{ }_{50}-\mathrm{VCL}_{25}-\mathrm{VAc}_{25}$ & VAc & 50 & 25 & 25 & - & 98 & 130 & 0.09 \\
\hline NIP-DVA $_{66}-\mathrm{VCL}_{17}-\mathrm{VAc}_{17}$ & VAc & 66 & 17 & 17 & - & 98 & 122 & 0.08 \\
\hline $\mathrm{MIP}-\mathrm{DVA} \mathrm{A}_{6}-\mathrm{VCL}_{47}-\mathrm{VAc}_{47}$ & VAc & 6 & 47 & 47 & 0.25 & 79 & 176 & 0.06 \\
\hline $\mathrm{MIP} \mathrm{DVA}{ }_{15}-\mathrm{VCL}_{42}-\mathrm{VAc}_{43}$ & VAc & 15 & 43 & 42 & 0.24 & 77 & 177 & 0.09 \\
\hline MIP-DVA $33-V_{3} L_{33}-V c_{34}$ & VAc & 33 & 34 & 33 & 0.25 & 86 & 174 & 0.09 \\
\hline $\mathrm{MIP} \mathrm{DVA} \mathrm{A}_{50}-\mathrm{VCL}_{25}-\mathrm{VAc}_{25}$ & VAc & 50 & 25 & 25 & 0.25 & 90 & 177 & 0.12 \\
\hline MIP-DVA $_{66}-\mathrm{VCL}_{17}-\mathrm{VAc}_{17}$ & VAc & 66 & 17 & 17 & 0.26 & 93 & 164 & 0.08 \\
\hline NIP-DVA $66^{-} \mathrm{VCL}_{34}$ & - & 66 & 34 & - & - & 99 & 167 & 0.08 \\
\hline MIP-DVA $_{66}-\mathrm{VCL}_{34}$ & - & 66 & 34 & - & 0.13 & 88 & 207 & 0.12 \\
\hline
\end{tabular}

${ }^{\mathrm{a}}$ Experimental conditions for miniemulsion polymerization: $2.2 \mathrm{wt}-\%$ of SDS surfactant, 2.0 wt- $\%$ of hexadecane co-surfactant, 4.0 mol- $\%$ of AIBN based on molar amount of monomers and crosslinker and 4.0 mol- $\%$ of $\mathrm{NaHCO}_{3}$ based on VCL. ${ }^{\mathrm{b}}$ The MIP and NIP samples are named MIP-DVA $-\mathrm{VCL}_{\mathrm{y}}-\mathrm{Co}-\mathrm{M}_{\mathrm{z}}$ and NIP-DVA $\mathrm{x}_{\mathrm{x}}-\mathrm{VCL}_{\mathrm{y}}-\mathrm{Co}_{\mathrm{z}} \mathrm{M}_{\mathrm{z}}$ with $\mathrm{x}, \mathrm{y}$ and $\mathrm{z}$ the mol- $\%$ of DVA, VCL and the liquid co-monomer respectively (Co-M = VAc, VeoVA-EH or VB). The mol- $\%$ is based on the total amount of VCL, DVA and Co-M. The polymerization temperature was $65^{\circ} \mathrm{C}$ except for VB copolymerization carried out at $80^{\circ} \mathrm{C} .{ }^{\mathrm{c}} X_{\mathrm{m}}$ is the overall conversion in double bonds determined by ${ }^{1} \mathrm{H}$ NMR for $6 \mathrm{~h}$ of polymerization. ${ }^{\mathrm{d}} D_{\mathrm{h}}$ and PDI are the hydrodynamic diameter and the polydispersity index determined by DLS. ${ }^{\mathrm{e}}$ Miniemulsion polymerization carried out at $80^{\circ} \mathrm{C}$. 
Thus, in order to further investigate the influence of the crosslinker on the colloidal features, a series of $\mathrm{P}(\mathrm{DVA}-\mathrm{co}$-VCL-co-VAc) colloidal MIPs and NIPs were synthesized with different crosslinker ratios, ranging from 6 mol-\% to 66 mol-\% (Table 1). The hydrodynamic diameter of NIP-DVA $-\mathrm{VCL}_{\mathrm{y}}-\mathrm{VAc}_{\mathrm{z}}$ decreased from $173 \mathrm{~nm}$ to $122 \mathrm{~nm}$ by increasing the DVA crosslinker ratio from 6 mol- $\%$ up to 66 mol-\%. At low crosslinker ratio, the crosslinked network of PVCL units surrounded by PVAc units still exhibits the well-established thermoresponsive swollen-to-collapse reversible transition of PVCL microgels (Figure S14 in SI). Due to the presence of hydrophobic PVAc units, the extent of swelling is lower for NIP$\mathrm{DVA}_{6}-\mathrm{VCL}_{47}-\mathrm{VAc}_{47}$ crosslinked with 6 mol- $\%$ of DVA (swelling ratio $=1.2$ ) compared to microgels of PVCL homopolymers. ${ }^{67}$ Increasing the crosslinking density hindered the swelling at room temperature and the thermoresponsive conformation change, which explained the lower $D_{\mathrm{h}}$ values measured at higher crosslinker ratios (Table 1). Such trend is not observed for MIP$\mathrm{DVA}_{\mathrm{x}}-\mathrm{VCL}_{\mathrm{y}}-\mathrm{VAc}_{\mathrm{z}}$ colloids loaded with the hydrophobic H-bonded NP as a constant average $D_{\mathrm{h}}$ values of $175 \mathrm{~nm}$ was measured for MIPs synthesized with 6 mol- $\%$ to 50 mol- $\%$ of DVA). Only a slight decrease of $5 \%$ of $D_{\mathrm{h}}$ to $164 \mathrm{~nm}$ was observed for MIP colloid synthesized with 66 mol- $\%$ of DVA.

\section{Specificity of colloidal MIP in NP adsorption: effect of medium polarity and polymer} network microstructure

One of the challenges for MIP materials is to provide sufficiently high adsorption yield while enabling a specific and selective adsorption of the targeted analyte. The specificity corresponds to the yield of adsorption of the analyte onto MIP compared to the adsorption yield of the corresponding NIP. This specificity is calculated with the imprinting factor ( $\alpha$, see Eq 3), and makes it possible to determine the influence of the molecular imprint on the adsorption. The selectivity is the ability of a MIP to promote a selective recognition of the target molecule 
compared to other molecules with close chemical structures. This selectivity is assessed by the selectivity coefficients and selectivity factor (Eq 4 and Eq 6). To address this challenge with the very hydrophobic nonylphenol pollutant $\left(\log \mathrm{K}_{\mathrm{OW}}(\mathrm{NP})=4.5\right),{ }^{6}$ it is of interest to investigate how the polarity of the adsorption medium would affect the specificity of adsorption onto the polymer colloids. As the final objective is to monitor the level of NP pollutant in river water via a pre-concentration by using colloidal MIPs, the presence of water in the adsorption medium is required to enable a simple post-addition of a miscible solvent. We thus investigated the effect of the solvent polarity on both the adsorption yield and the imprinting factor (Figure 2) by varying compositions of hydroalcoholic mixtures from $100 / 0 \mathrm{v} / \mathrm{v} \mathrm{H}_{2} \mathrm{O} / \mathrm{EtOH}$ to $0 / 100$ $\mathrm{H}_{2} \mathrm{O} / \mathrm{EtOH}$ v/v. The corresponding adsorption capacities are plotted in Figure S15 and Figure $\mathbf{S 1 6}$ in SI. In a relative polarity scale, ethanol is associated with a relative polarity of 0.65 for polarity of water of $1.00 .{ }^{71}$ It should be noticed that due to the low limit concentration of NP solubility in water $\left([\mathrm{NP}]_{\mathrm{H} 20}<2.2 \times 10^{-5} \mathrm{~mol}^{-L^{-1}}\right){ }^{6}$ the adsorption experiments of NP onto NIP and MIP particles dispersed in $100 \%$ of water were carried out with highly diluted solutions of $\mathrm{NP}$ at concentrations at $1 \mathrm{ppm}$ instead of $110 \mathrm{ppm}$ for NP in hydroalcoholic media. As described in the experimental section, the low concentrations of NP in water were monitored by GC-MS method in order to accurately calculate the adsorption capacity $(Q, \mathrm{Eq} 1)$ and the adsorption yield of NP (Eq 2). This required a careful cleaning procedure of the MIP particles after their synthesis in order to reach a residual concentration of NP down to tens of ppb $\left(\mu \mathrm{g} . \mathrm{L}^{-1}\right)$ in the supernatant (see Table S4 in SI). The higher solubility of NP in hydroalcoholic solution enabled us to implement a more straightforward quantification of NP by UV-visible spectroscopy as the initial concentration of NP was close to $110 \mathrm{ppm}$. 

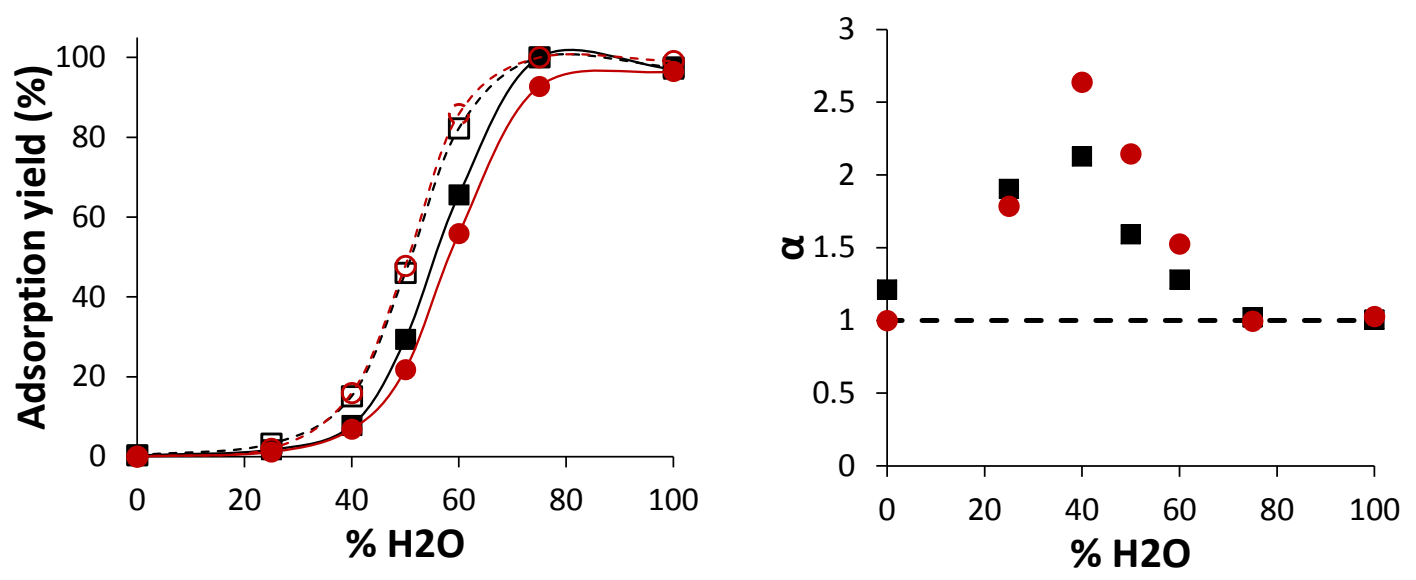

Figure 2 . Adsorption yield of $\mathrm{NP}$ onto $\mathrm{DVA}_{33^{-}}-\mathrm{VCL}_{33^{-}}-\mathrm{VAc}_{34}$ (black squares) and $\mathrm{DVA}_{66^{-}}$ $\mathrm{VCL}_{17}-\mathrm{VAc}_{17}$ (red circles) MIP (empty symbols) and NIP (plain symbols) colloids (Left) and values of imprinting factor $(\alpha)$ (right) as function of water volumic fraction in the hydroalcoholic solvent.

The adsorption of NP in water onto MIP and NIP particles was very fast and reached adsorption yields above $90 \%$ (Figure 2 and Figure S16 in SI). The equivalent adsorption yields for both MIP and NIP indicates a non-specific adsorption of NP $(\alpha=1)$ whatever the crosslinker content. It has been previously reported that MIPs for small organic molecules are hardly selective in pure water due to the predominance of the hydrophobic interactions reducing the specificity of the adsorption. ${ }^{20}$ With the attempt to reduce the hydrophobic effect in the binding process of the NP with the MIPs and NIPs synthesized with VAc as co-monomer, the polarity of the solvent was tuned by adding ethanol into water. The binding properties of the series of MIPs and corresponding NIPs synthesized were investigated in mixtures of ethanol and water. Figure 2 highlights an increase of the adsorption yield by increasing the water content. The adsorption with high fraction of water is mainly driven by hydrophobic interactions of NP on the hydrophobic polymer network, which minimizes the specificity of the recognition. For instance, by adding $50 \%$ of ethanol, the yield of adsorption of NP by the MIP-DVA ${ }_{33}-\mathrm{VCL}_{33}-\mathrm{VAc}_{34}$ decreased to $46 \%$ while it was complete $(97 \%)$ in pure water for a similar MIP. For a water 
content ranging between $25 \%$ and $50 \%$, the specific recognition arising from the imprinting is efficient as the imprinting factor is above 1.5. The most efficient specific recognition is observed for $40 \%$ of water but the adsorption yield is rather low. The best compromise between a specific recognition, ie high imprinting factor, and sufficiently high adsorption yield in observed for $50-60 \mathrm{wt}-\%$ of water. On the other hand, the specificity is lost in ethanol as the affinity of NP for the continuous phase is too high and the adsorption yield is consequently very low. This was expected as ethanol is used to efficiently desorb NP from MIP. The range of the imprinting factor (Figure 2) for the present MIPs is the sign of high level of specificity as compared with the values reported in the literature. Herein, the maximum $\alpha$ value was 2.6 in 40/60 water/ethanol and 2.1 in 50/50 v/v water/ethanol with 66 mol.- $\%$ of crosslinker. Pan et $a l .{ }^{43}$ synthesized a MIP for the NP using MAA and EGDMA as functional monomer and crosslinker respectively. The imprinting factor obtained was 1.3 in water/ethanol mixture 50/50 (v/v). Guerreiro et al. ${ }^{11}$ compared different amino and acidic monomers such as methacrylic acid, itaconic acid, 4-vinylpyridine (4-VP) or dimethyl aminoethyl methacrylate (DEAEMA) for the binding of nonylphenol. The highest specificity $(\alpha=3.02)$ was observed with the PDEAEMA-based MIP in a mixture of $80 / 20 \mathrm{v} / \mathrm{v}$ acetonitrile/water but it dropped to 1.5 in $60 / 40 \mathrm{v} / \mathrm{v}$ acetonitrile/water. The specificity of $\mathrm{P}(4-\mathrm{VP})$-based MIP for $p$ - $t$-octylphenol ranged between $1.3-1.7$ by using a phosphate buffer/water 50/50 v/v. ${ }^{72}$ Higher MIP imprinting factors of 1.8 to 3.2 were observed for NP adsorption carried out in alcoholic solvents free of water. ${ }^{45}$, 46 These results converged with our observation that increasing the solvent polarity by adding water reduces the specificity of the recognition by MIP due to the enhancement of the hydrophobic non-selective interaction. With the objective to pre-concentrate NP from aqueous effluents, we successfully managed in the present work to achieve high efficiency of the imprinting $(\alpha>2)$, even in the presence of 40 to $50 \%$ of water in the adsorption media. The specific recognition of NP by MIP-DVA-VCL-VAc particles is enhanced in the binding process 
when the affinity of the NP with the solvent and the hydrophobic interaction of NP with the polymer colloid are well-balanced. A high crosslinking density is expected to produce homogeneous cavities during the imprinting process, in terms of shape and size. Lower crosslinking density allows solvent diffusion in the polymer network, which induces deformation of the imprint by swelling and so reduces the specific recognition. As depicted Figure 2, a higher DVA crosslinker ratio imparted a better specificity with higher imprinting factors for the MIP-DVA-VCL-VAc colloids synthesized with 66 mol- $\%$ of DVA crosslinker instead of 33 mol- $\%$. The comparison of $\alpha$ for two additional crosslinker fractions of $15 \%$ and $50 \%$ in hydroalcoholic mixtures is displayed in Figure S17 in ESI.

We highlighted that decreasing the polarity of the adsorption media was a key parameter to improve the specificity of the recognition but at the expense of the adsorption capacity of NP onto the polymer colloids. Another way to increase the adsorption of NP is to tune the chemical composition of the polymer by varying the hydrophobicity of the co-monomers used for MIP synthesis. For that purpose, three different vinyl ester monomers (VeoVA-EH, VB or VAc) with various octanol-water partition coefficients $\left(\log \mathrm{K}_{\mathrm{OW}}\right)$ were selected as less activated monomers to be efficiently copolymerized with $N$-vinylcaprolactam monomer and divinyl adipate crosslinker (see Scheme 1). In order to provide the range of hydrophobicity, the octanolwater partition coefficient $\left(K_{\mathrm{ow}}\right)$ for this series of monomers was calculated from their chemical structure using PubChem software in order to assess the increasing hydrophobicity: $\log K_{\text {ow }}=$ 0.7 for $\mathrm{VAc}, \log K_{\mathrm{ow}}=1.2$ for $\mathrm{VCL}, \log K_{\mathrm{ow}}=2.2$ for $\mathrm{VB}$ and $\log K_{\mathrm{ow}}=3.6$ for VeoVA. The calculation was supported by a close value of $\log K_{\mathrm{ow}}$ of 0.73 reported in the literature for VAc monomer. ${ }^{73}$ Figure 3 provides an overview of the concomitant effects of solvent polarity and co-monomer hydrophobicity on both parameters, namely adsorption yield and imprinting factor. The corresponding adsorption capacities are reported in Figure S18 in SI. 

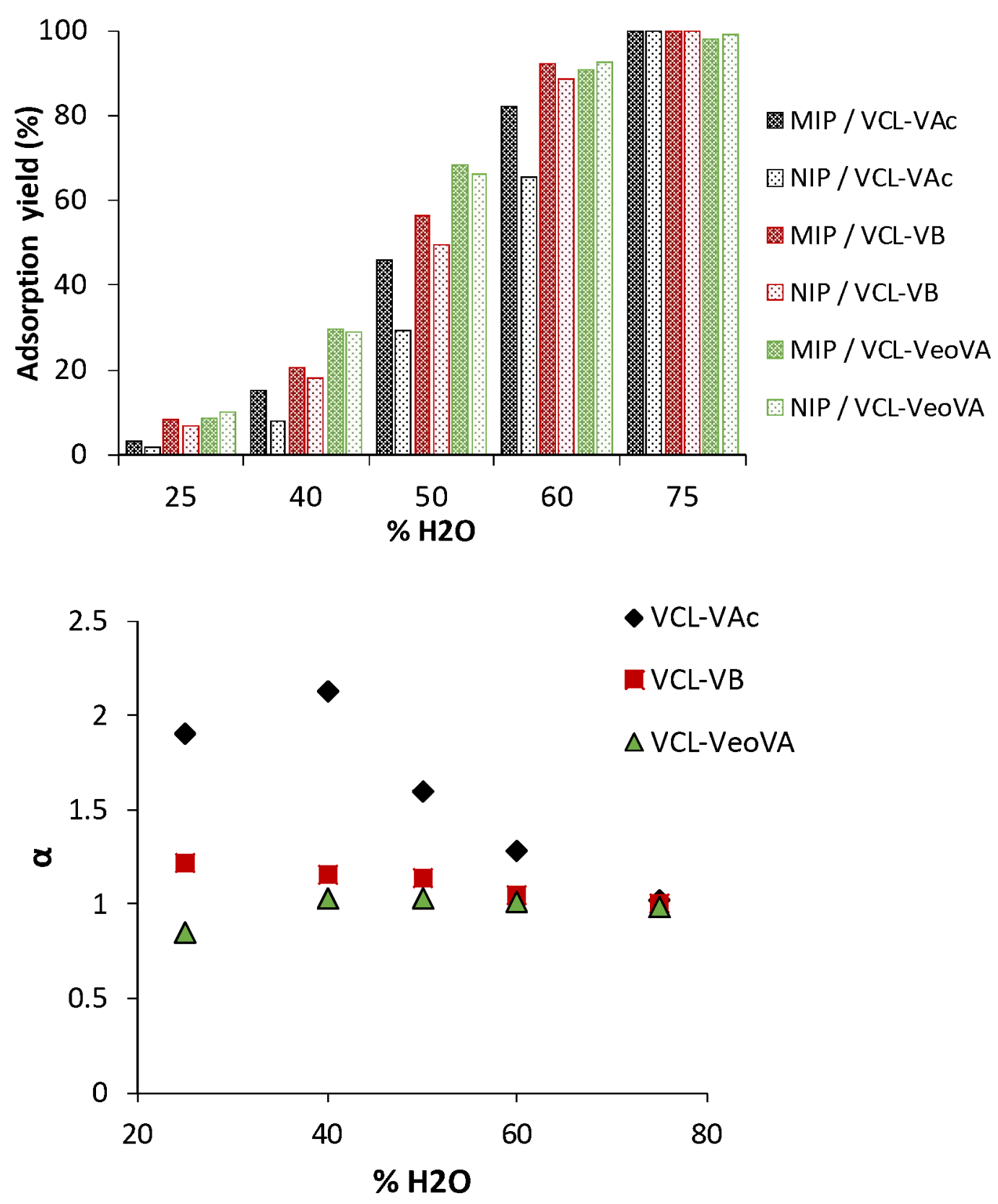

Figure 3. Top) Adsorption yield and Bottom) corresponding imprinting factor ( $\alpha$ ) at different water contents of a series of NIP-DVA $33-\mathrm{VCL}_{33}-\mathrm{M}$ and MIP-DVA $3 \mathrm{HCL}_{33}-\mathrm{M}$ crosslinked with $33 \%$ DVA, with $\mathrm{M}=$ VAc, VB or VeoVA co-monomer. Adsorption of NP $\left([\mathrm{NP}]_{0}=0.5\right.$ mmol.L $\left.\mathrm{L}^{-1}, 110 \mathrm{ppm}\right)$ measured for $[\mathrm{MIP}]=[\mathrm{NIP}]_{0}=10 \mathrm{~g} \cdot \mathrm{L}^{-1}$. 
The adsorption yield steadily increases with both hydrophobicity of the co-monomer and solvent polarity while the imprinted factors varied in the opposite trend (Figure 3). This trend is particularly obvious at 40 and $50 \%$ of water. The overall binding can be divided in two different processes: specific binding arising from the imprinted cavities in the MIP polymer network and non-specific binding to the polymer colloids due to hydrophobic interactions. ${ }^{20}$ Thus, in case of VeoVA-EH, the hydrophobic effect predominates and the total binding was driven by non-specific interactions $(\alpha=1)$ whereas the less hydrophobic VAc induced more specific interactions with the MIP $\left(\alpha_{\max }=2.2\right)$. VB comonomer with intermediate hydrophobicity showed moderate imprinting factor but still too low to claim sufficient specificity $\left(\alpha_{\max }=1.2\right)$. Finally, we investigated the role of the added co-monomer by monitoring the level of NP adsorption and its specificity onto colloids of PVCL alone compared to P(VCL-co-VAc) colloids, both crosslinked with 66 mol-\% of DVA (see Figure S19 in ESI). The specificity of $\mathrm{DVA}_{66}-\mathrm{VCL}_{34}$ colloids is lowered compared to the $\mathrm{DVA}_{66}-\mathrm{VCL}_{17}-\mathrm{VAc}_{17}$. It should be mentioned that the hydrophobicity of the VCL is slightly higher than that of the VAc based on the values of octanol-water partition coefficient $\left(\log \mathrm{K}_{\mathrm{OW}, \mathrm{VAc}}=0.7, \log \mathrm{K}_{\mathrm{OW}, \mathrm{VCL}}=\right.$ 1.2). As we introduced 25 mol- $\%$ of NP versus VCL for the MIP synthesis, the number of Hbonding monomer is at least 4 times higher even in DVA-VCL-VAc MIPs. So, replacing VAc by VCL contributes to enhancing the non-selective adsorption via hydrophobic interaction. In conclusion of this part, copolymerizing VAc with VCL in the presence of DVA crosslinker turns to be the most efficient system to promote specific and quantitative recognition of nonylphenol in hydroalcoholic media. In combination with the H-bonding promoter VCL monomer, the hydrophobicity of VAc co-monomer provides the best balance between a sufficiently high adsorption yield and the best specificity of the imprinting towards nonylphenol in $50 / 50 \mathrm{v} / \mathrm{v} \mathrm{H}_{2} \mathrm{O} / \mathrm{EtOH}$. 


\section{Investigation of the binding features of nonylphenol, selectivity and desorption}

The Langmuir ${ }^{74}$ and Freundlich ${ }^{75}$ models were developed to rationalize the adsorption isotherms of molecules in solution.

The Langmuir model (Eq 10) considered a homogeneous surface with a monolayer adsorption for each site in the absence of interactions between adsorbed molecules in this site. The terms $Q$ and $C_{\text {eq }}$ were defined in Eq 1

- $Q_{\max }$ is the theoretical maximum monolayer adsorption capacity $\left(\mathrm{mg}^{\mathrm{g}} \mathrm{g}^{-1}\right), K_{L}$ is the Langmuir adsorption equilibrium constant $\left(\mathrm{L} . \mathrm{mg}^{-1}\right)$, related to the affinity of adsorption sites.

$Q=Q_{\max } \frac{K_{L} C_{e q}}{1+K_{L} C_{e q}}$

Eq 10

The Freundlich model (Eq 11) considered the heterogeneity of the surface and multilayer adsorption. The empirical parameter $n$ is the estimate of deviation from the linearity of adsorption. $K_{F}$ is the Freundlich adsorption equilibrium constant $\left(\mathrm{mg}^{1-1 / n} \mathrm{~L}^{1 / n} \mathrm{~g}^{-1}\right)$, and $n$ is related to adsorption intensity. When the heterogeneity index $1 / n$ is below 1 , the adsorption is related to a normal Langmuir adsorption, otherwise it is related to cooperative adsorption. ${ }^{76}$ $Q=K_{F} C_{e q}^{1 / n}$

\section{Eq 11}

Considering the Langmuir model, the Langmuir equation can be expressed with a dimensionless separation factor called separation factor $R_{L}$ (Eq 12). ${ }^{77}$ Depending on the value of $R_{L}$, the adsorption is either irreversible $\left(R_{L}=0\right)$, favourable $\left(0<R_{L}<1\right)$, linear $\left(R_{L}=1\right)$ or unfavourable $\left(R_{L}>1\right)$.

$R_{L}=\frac{1}{1+K_{L} C_{0}}$

Eq 12

Both the maximum monolayer adsorption capacity $\left(Q_{\max }\right)$ and the dissociation constant $\left(K_{D}\right.$ in mol. $\mathrm{L}^{-1}$ ) of the binding sites can also be calculated by using Scatchard ${ }^{78}$ plot analysis (Eq 13). 
$\frac{Q}{C_{e q}}=\frac{Q_{\max }-Q}{K_{D}}$

Eq 13

The experimental adsorption isotherms of NP onto the MIP-DVA $66-\mathrm{VCL}_{17}-\mathrm{VAc}_{17}$ were fitted according to Langmuir, Freundlich and Scatchard equations in Figure S24 in SI. Non-linear least squares method was applied to extract the parameters for Langmuir and Freundlich equations (

Table 2). The linear regression fit of the Scatchard equation was reliable $\left(\mathrm{R}^{2}=0.9892\right.$, Figure S24 in SI) to calculate the dissociation constant $\left(K_{D}\right)$ and association constant $\left(K_{A}=1 / K_{D}\right)$. As the Langmuir isotherm model better fitted the experimental data compared to the Freundlich isotherm model, a monosite adsorption of NP can be suggested. This result is consistent with the Scatchard plots exhibiting linear plots with only one slope as an indication of a simple class of binding sites. ${ }^{79}$ Moreover, the value of $n$ determined with the Freundlich model indicates that the term $1 / n$ is smaller than 1 , describing a Langmuir adsorption (

Table 2).

Table 2. Adsorption isotherm parameters determined for NP adsorption onto MIP-DVA $66^{-}$ $\mathrm{VCL}_{17}-\mathrm{VAc}_{17}$ in $50 / 50 \mathrm{v} / \mathrm{v}$ water/ethanol mixture.

\begin{tabular}{|c|c|c|c|c|c|c|c|}
\hline Model & & & & eundlich & & ard & \\
\hline Constants & $\begin{array}{c}Q_{\max } \\
\left(\mathrm{mg} \cdot \mathrm{g}^{-1}\right)\end{array}$ & $\begin{array}{c}K_{\mathrm{L}} \\
\left(\mathrm{L} . \mathrm{mol}^{-1}\right)\end{array}$ & $1 / n$ & $\begin{array}{c}K_{\mathrm{F}} \\
\left(m g^{1-1 / n} \cdot \mathrm{L}^{1 / n} \cdot \mathrm{g}^{-1}\right)\end{array}$ & $\begin{array}{c}Q_{\max } \\
\left(\mathrm{mg} \cdot \mathrm{g}^{-1}\right)\end{array}$ & $\begin{array}{c}K_{\mathrm{D}} \\
\left(\mathrm{mol} . \mathrm{L}^{-1}\right)\end{array}$ & $\begin{array}{c}K_{\mathrm{A}} \\
\left(\mathrm{L} . \mathrm{mol}^{-1}\right)\end{array}$ \\
\hline Results & 174 & 286 & 0.44 & 4.02 & 174 & $3.3 \times 10^{-3}$ & 297 \\
\hline
\end{tabular}


The fits of Langmuir and Scatchard both provided an average value of $Q_{\max }$ of $174 \pm 25 \mathrm{mg} . \mathrm{g}^{-}$ ${ }^{1}$, ie 0.8 mmol.g-1

Table 2). This value, far beyond values previously reported in other studies ${ }^{41,} 45$ about NP adsorption onto $\mathrm{P}(4-\mathrm{VP})$-based MIPs $\left(7<Q_{\max }<50 \mathrm{mg} \mathrm{g}^{-1}\right)$, confirms the interest of the present colloidal MIPs. The separation factor $R_{L}$ ranges from 0.87 to 0.15 , meaning that the adsorption of NP is favoured in the present range of the concentration. The association constant of NP onto MIP-DVA 66 -VCL $17-\mathrm{VAc}_{17}$ was in the range of $290 \mathrm{~L} \cdot \mathrm{mol}^{-1}$, as calculated by both the Langmuir $\left(K_{\mathrm{L}}\right)$ and Scatchard analysis plots $\left(K_{\mathrm{A}}\right)($

Table 2).

Isothermal calorimetry (ITC) is a robust method to characterize the binding mechanism of the nonylphenol (NP) with the different MIPs and NIPs. ITC is a very sensitive technique based on heat change detection occurring in ligand-receptor interactions. ITC has already been successfully applied to MIP characterization. ${ }^{80-82}$ Here, the interaction of NP with imprinted and non-imprinted polymer particles was investigated in mixture of ethanol/water $50 / 50(\mathrm{v} / \mathrm{v})$ at $25^{\circ} \mathrm{C}$. ITC allows to measure the enthalpic contribution of NP binding and the association constant $\left(K_{\mathrm{A}}\right)$. The Gibbs free energy $(\Delta \mathrm{G})$ and the entropy $(\Delta \mathrm{S})$ are thus calculated (see experimental part) and reported in Table 3).

Table 3. Thermodynamic data for binding nonylphenol to MIPs and NIPs with 33 mol.\% of crosslinker determined by ITC at $25^{\circ} \mathrm{C}\left(\mathrm{H}_{2} 0 / \mathrm{EtOH} 50 / 50 \mathrm{v} / \mathrm{v}\right.$ mixtures with MQ-water at $\mathrm{pH}$ 6-7).

\begin{tabular}{|c|c|c|c|c|}
\hline Sample & $\begin{array}{c}\Delta G \\
\left(\text { kcal.mol }^{-1}\right)\end{array}$ & $\begin{array}{c}\Delta H \\
\left(\text { kcal.mol}^{-1}\right)\end{array}$ & $\begin{array}{c}\Delta S \\
\left(\text { cal. }^{-1} \cdot \mathrm{mol}^{-1}\right)\end{array}$ & $\begin{array}{c}K_{\mathrm{A}} \\
\left(\mathrm{L} . \mathrm{mol}^{-1}\right)\end{array}$ \\
\hline NIP-DVA $33-V_{33}-V_{3 c_{34}}$ & -2.8 & -4.0 & -4.2 & 109 \\
\hline MIP-DVA $33^{-}-\mathrm{VCL}_{33}-\mathrm{VAc}_{34}$ & -2.6 & -11.4 & -29.4 & 85 \\
\hline
\end{tabular}


1

\begin{tabular}{ccccc}
\hline NIP-DVA $_{33}-\mathrm{VCL}_{34}-\mathrm{VB}_{33}$ & -2.6 & -11.6 & -30.1 & 84 \\
MIP-DVA $_{33}-\mathrm{VCL}_{34}-\mathrm{VB}_{33}$ & -2.4 & -25.7 & -78.0 & 58 \\
\hline $\mathrm{NIP}-\mathrm{DVA}_{32}-\mathrm{VCL}_{32}-\mathrm{VeoVA}_{36}$ & -2.6 & -36.7 & -114.0 & 83 \\
$\mathrm{MIP} \mathrm{DVA}_{34}-\mathrm{VCL}_{33}-\mathrm{VeoVA}_{33}$ & -2.6 & -47.5 & -151.0 & 78 \\
\hline
\end{tabular}

The adsorption of NP is a favourable process as the Gibbs free energy of the NP binding is negative (see Table 3). The binding process is driven by the enthalpy factor $(\Delta \mathrm{H}<0)$ with reversible hydrogen bonding favourable at low temperature where the exothermicity is predominant but unfavourable by increasing temperature as the term $-T \Delta S$ is positive (Figure 4 and Table 3). The higher absolute value of enthalpy of binding for MIP compared to NIP confirmed the stronger interaction of NP with MIPs and so the successful role of imprinting. The negative enthalpy is probably due to different contributions: adsorption of NP with recognition sites through $\mathrm{H}$-bonding and solvent recovering the hydrogen bonds when NP molecule is withdrawn from solution during adsorption onto biding sites. 

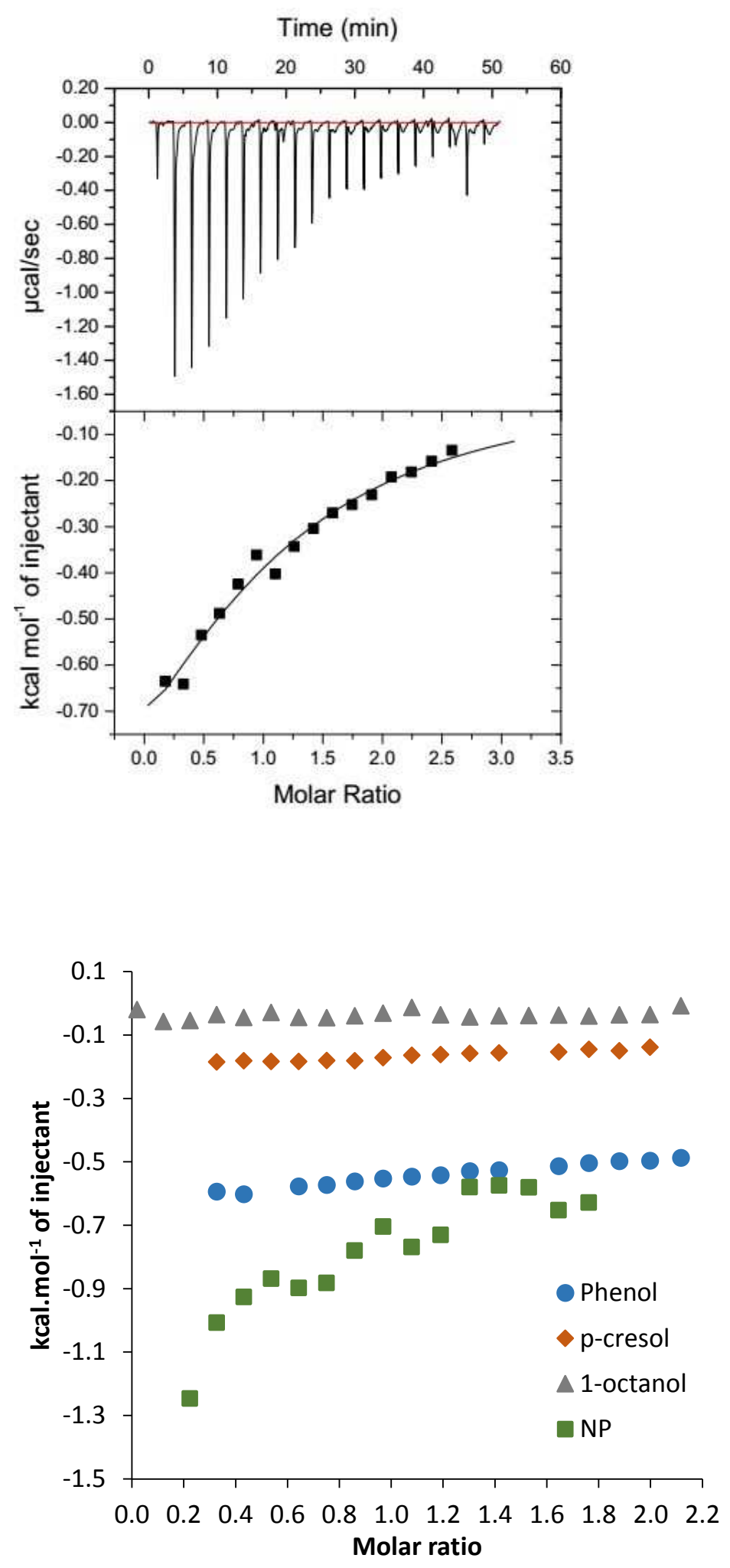

Figure 4. Top) Titration of $20 \mathrm{mM}$ of nonylphenol with MIP-DVA $50^{-} \mathrm{VCL}_{25}-\mathrm{VAc}_{25}$ at 5 g.L $\mathrm{L}^{-1}$ in ethanol/water 50/50 v:v at $25^{\circ} \mathrm{C}$; Bottom) comparison of ITC traces for titration of NP (green 
squares), 1-octanol (grey triangles), p-cresol (red diamonds) and phenol (blue dots) with MIP$\mathrm{DVA}_{50}-\mathrm{VCL}_{25}-\mathrm{VAc}_{25}$. 
The binding constant provides information about the nature of interactions. The association constant $\left(K_{\mathrm{A}}\right)$ is similar for both MIP and NIP, which comprise of same monomers (Table 3). Nonylphenol indeed shows a similar type of binding affinity with the different particles as all the experimental data of $\Delta \mathrm{H}$ versus $\Delta \mathrm{S}$ are in a same line, but with a different thermodynamic profile (Figure 5). It can be noted that the equilibrium physisorption exhibits $K_{\mathrm{A}}$ values in a low range of 60 and $100 \mathrm{~L}^{\mathrm{mol}}{ }^{-1}$. This is consistent with the fact that NP has only one group able to form hydrogen bonds, the rest of the molecule is hydrophobic and the hydrophobic interactions does not have any preferred directions. The fit of adsorption isotherms introduced earlier in this work also provided value of $K_{\mathrm{A}}$ also in a hundred L.mol-1 range. It can be noticed that both absolute values of enthalpy increased with the increase of the comonomer hydrophobicity so the hydrophobic interaction play a key role in the adsorption (Figure 5). Moreover, the standard deviation of the enthalpy between MIP and NIP increases from $20 \%$ to $70 \%$ in the VAc $>\mathrm{VB}>\mathrm{VeoVA}$ range, which confirms the beforehand conclusion of the interest of the co-monomer VAc to promote a more specific binding of NP (Figure 5).

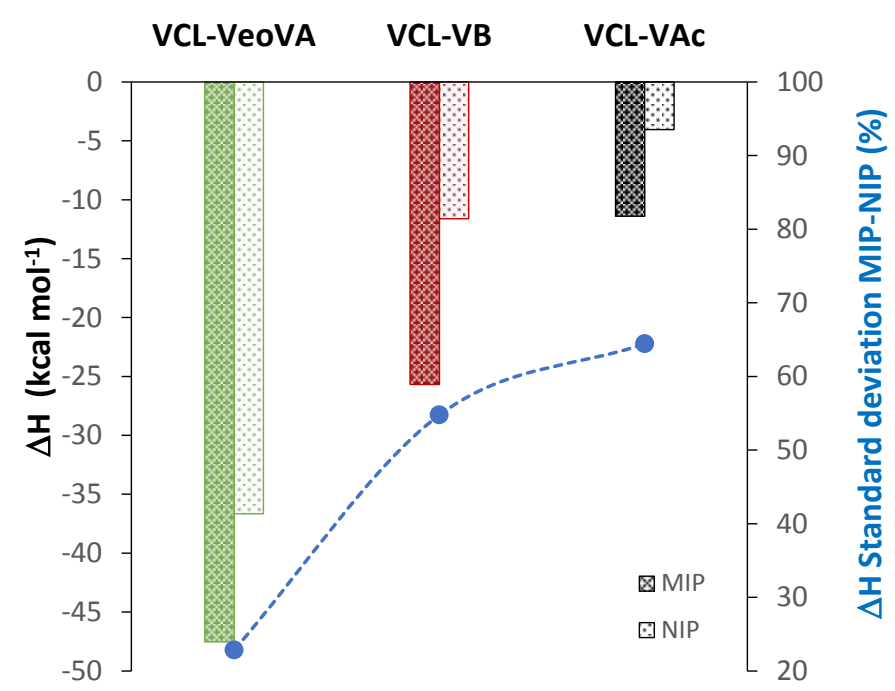




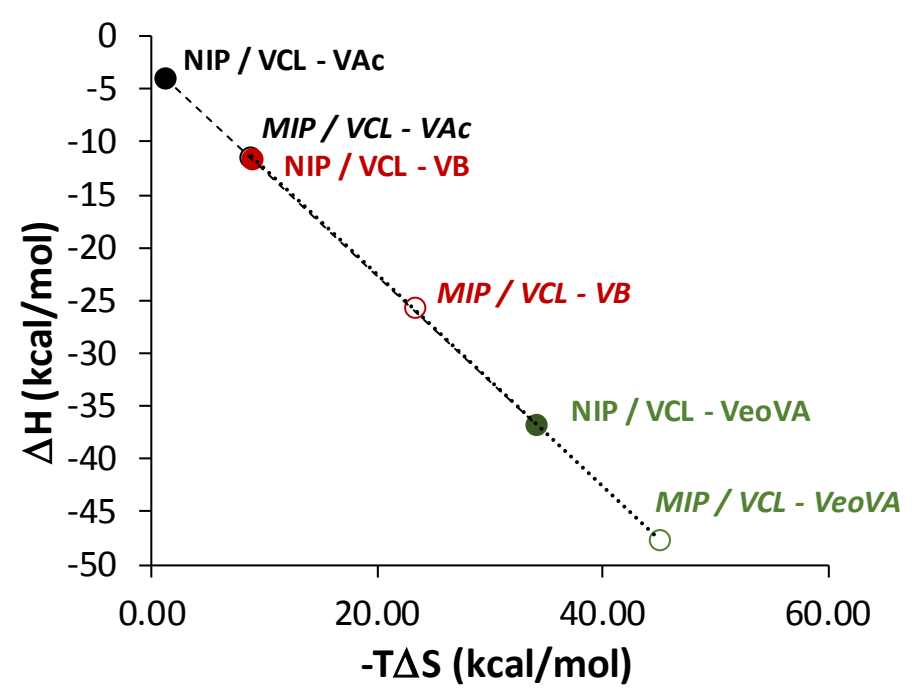

Figure 5: (Top) Histogram of enthalpy of binding and (blue dots) standard enthalpy deviation between MIP and NIP and (bottom) enthalpic contribution plotted as a function of entropic contribution for the binding of nonylphenol with MIPs (empty symbols) and NIPs (plain symbols) containing different co-monomers. Binding in $\mathrm{H}_{2} \mathrm{O} / \mathrm{EtOH} 50 / 50 \mathrm{v} / \mathrm{v}$ at $25^{\circ} \mathrm{C}$.

In the present work, the adsorption of NP is systematically associated with a negative entropy. It has been reported in the literature that desolvation of the solute during adsorption is associated with a positive entropy, especially for polar systems where the solvent molecules are oriented around the solute. ${ }^{21,82}$ Such adsorption of polar molecules has shown to be entropically driven as the attraction with cavity was weak (low enthalpy). ${ }^{21,82}$ On the other hand, for interaction of ionic substances corresponding to a strong attraction between solute and cavity, entropy is often negative when the sorption takes place by recombination of charges and the solute is removed from the solution by Coulomb force. ${ }^{83}$ The binding of amphiphilic molecules is different and the present work highlights a structuring effect of the adsorption of NP on the cavity surface $(\Delta \mathrm{S}<0)$. The contribution of desolvation seems to be minor as NP has only one hydroxyl group and there is no restriction to the solvent mobility close to the hydrophobic part that does not have orientation effect. Based on its chemical structure (Scheme 1), nonylphenol is amphiphilic molecule, prone to different types of interactions: hydrogen bonding from hydroxyl group, 
hydrophobic interaction from aliphatic chain, $\pi-\pi$ stacking from aromatic group, Coulomb interaction in case of hydroxyl ionic dissociation. In order to figure out the potential role of each chemical group, four different molecules were titrated with the solvent: phenol, $p$-cresol, 1-octanol and nonylphenol (see Figure S20 in SI). The dilution is endothermic but to a far smaller extent for phenol and $p$-cresol compared to NP, so the contribution of $\pi-\pi$ stacking is rather minor. On the other hand, dilution of 1-octanol, is also endothermic of higher energy than for phenol and $p$-cresol but still far lower than for NP, hence showing the impact of hydrophobic chain. Most of the interactions in polar solvents are solvent-mediated. Indeed, the titration of NP with MIP-DVA $50^{-} \mathrm{VCL}_{25}-\mathrm{VAc}_{25}$ in acetonitrile, an aprotic solvent forming strong hydrogen bonds with protic substance but very weak hydrogen bonds with itself, showed no interaction of NP with MIP (Figure S21 in SI). Polar solvent is essential for adsorption of NP onto the present crosslinked particles. Concerning the interaction of these molecules with both MIP and NIP, the interaction of 1-octanol, a less acidic aliphatic alcohol compared to phenolic groups of NP, phenol and $p$-cresol demonstrated either very weak or no binding with DVA-VCL-VAc colloids (Figure 4 and Figure S22 in SI). It should be noticed that Coulomb interactions can take place to the adsorption concomitantly to H-bonding interactions. Indeed, while negative entropy values were systematically observed in $\mathrm{H}_{2} \mathrm{O} / \mathrm{EtOH} 50 / 50 \mathrm{v} / \mathrm{v}$ with water at neutral (Table 3) or alkaline $\mathrm{pH}(\mathrm{pH}$ 10.7, Figure S23 in SI) a positive entropy value was measured for water at $\mathrm{pH} 3$ (Figure $\mathbf{S 2 3}$ in SI). This result suggests that in acidic $\mathrm{pH}$, «pure » hydrophobic/H-bonding interactions occur while at higher $\mathrm{pH}$ some Coulomb interactions might start to contribute for NP adsorption.

In conclusion of the ITC study, neither hydrophobic fragment alone nor phenolic fragment alone are enough for binding to the polymer colloids. Only the presence of both phenolic and aliphatic fragment in one molecule like in NP results in strong binding, exothermic with negative entropy. Such selectivity of MIP colloids towards NP compared to 1-octanol, phenol 
and $p$-cresol is also qualitatively observed by ITC for VeoVA and VB-based MIP (Figure S27). Among this selectivity, the strength of binding is higher for MIP compared to NIP so the imprinting is successful.

In order to confirm the selectivity of the optimized MIPs toward NP, quantitative adsorption experiments by UV-visible spectroscopy were carried out to compare the adsorption capacity of nonylphenol and phenol onto MIP or NIP. The selectivity coefficients of the colloids are above unity (Figure 6) showing the preferential adsorption of the targeted NP pollutant.

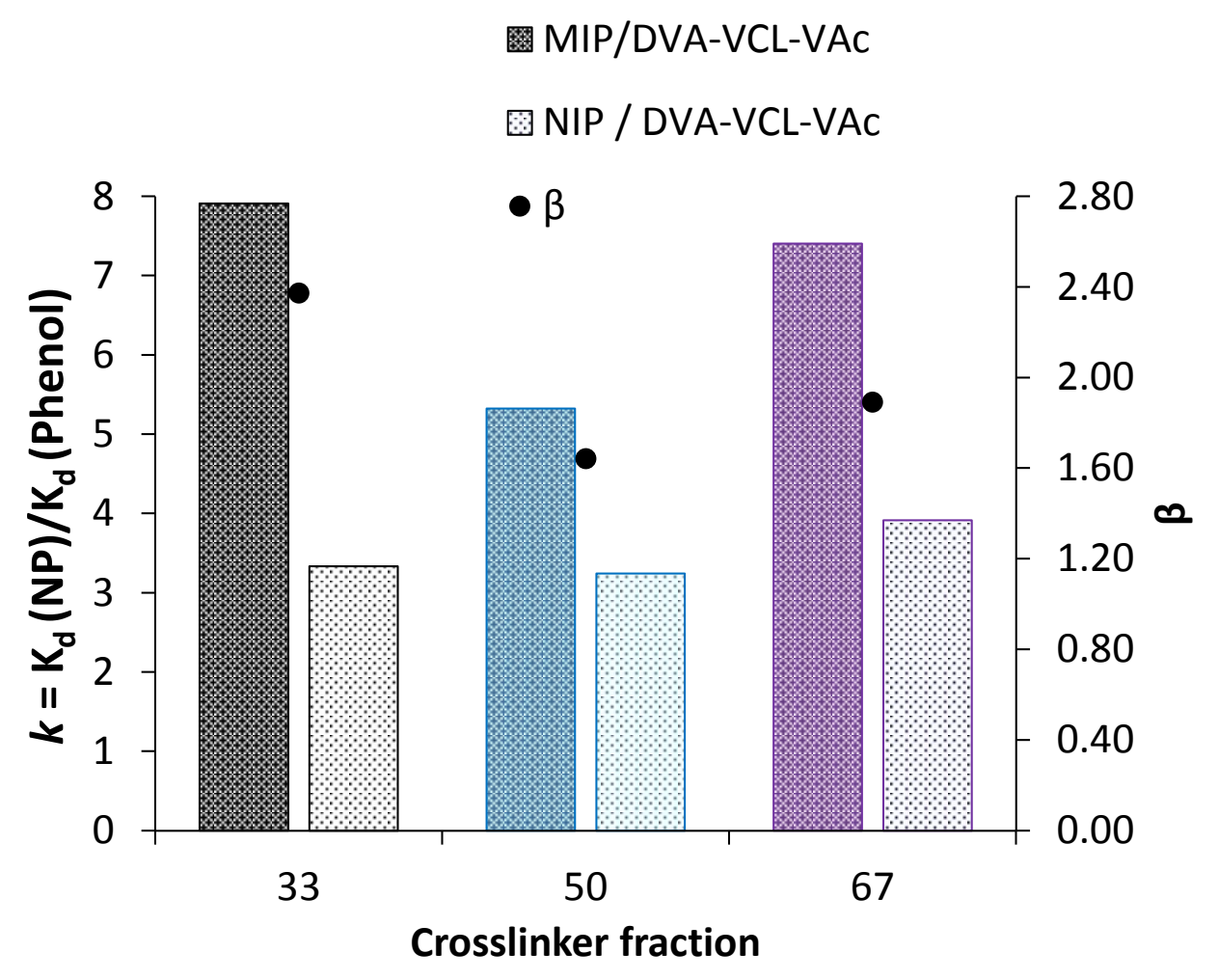

Figure 6. Histograms of selectivity coefficient $(k)$ and relative selectivity factor ( $\beta$, black dots) for the adsorption of nonylphenol and phenol onto MIP/NIP-VAc $-\mathrm{VCL}_{\mathrm{y}}-\mathrm{DVA}_{\mathrm{z}}$ with different crosslinker fractions.

The relative selectivity factor $(\beta)$ compares the ratio of the selectivity coefficients between MIP and NIP (Eq 6Eq 6), which more accurately depicts an effect of the imprint rather than the sole 
hydrophobic effect on the adsorption of both molecules onto colloids. Values of $\beta$ ranging between 1.6 and 2.4 confirms the efficiency of MIPs in a preferential recognition of NP over phenol.

\section{Desorption of Nonylphenol from MIPs}

Since the objective of the present work was to design imprinted submicronic colloids for specific pre-concentration of NP prior its detection, it is of importance to study the experimental parameters affecting the desorption yield of NP. The MIP-DVA $66-\mathrm{VCL}_{17}-\mathrm{VAc}_{17}$ was used to adsorb NP in 50/50 (v/v) water/ethanol mixture prior to monitor the desorption yield in ethanol (Figure S25 in SI). It should be first noticed that a minimum of $85 \%$ of the NP adsorbed was recovered by desorption in ethanol. Ultrasonication increased slightly the desorption yield from $88 \%$ to $91 \%$. More interestingly, the effect of the temperature was more effective with a desorption yield up to $100 \%$ at $50^{\circ} \mathrm{C}$. Similar results were obtained with MIP using VCL as monomer, ${ }^{57}$ which was ascribed by the authors to thermoresponsive behavior of PVCL despite the fact that the MIP is synthesized at high temperature. In the present work, desorption was carried out in ethanol where thermoresponsiveness of PVCL does not take place. The ITC

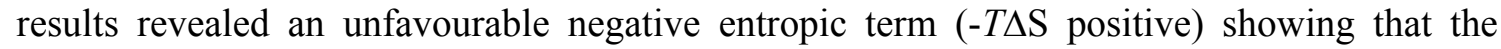
reverse dissociation process is more favoured by increasing temperature.

\section{Conclusion}

This work reports the successful synthesis in aqueous dispersed media of stable imprinted polymer colloids of $200 \mathrm{~nm}$ size for nonylphenol specific recognition. Tuning the solvent polarity and the hydrophobicity of the co-monomer used with $\mathrm{N}$-vinylcaprolactam in miniemulsion polymerization is crucial to achieve the best compromise between a sufficient adsorption capacity by hydrophobic interactions but still with specificity of adsorption. The adsorption of nonylphenol onto MIP-DVA-VCL-VAc with $50-66 \%$ of DVA crosslinker in $50 / 50 \mathrm{EtOH} / \mathrm{H}_{2} \mathrm{O} \mathrm{v} / \mathrm{v}$ mixture proved to be the most efficient system to promote specificity of 
MIPs compared to NIPs. Higher imprinting factor of $\alpha=1.5-2.3$ were observed. This imprinting specificity was confirmed by the higher enthalpy of binding for MIP. Also the highest enthalpy standard deviation between MIP and NIP for colloids based on VCL/VAc compared to VCL/VB or VCL/VeOVA were in agreement with the best efficiency of VAc comonomer. The binding is enthalpy-driven and proceeds via homogeneous monolayer adsorption. Adsorption isotherms described a monolayer homogeneous Langmuir adsorption with binding constant $\left(K_{\mathrm{A}}\right)$ of ca $300 \mathrm{~L} \cdot \mathrm{mol}^{-1}$, in a similar range of $K_{\mathrm{A}}\left(100 \mathrm{~L}^{\mathrm{mol}}{ }^{-1}\right)$ calculated from ITC measurements based on monosite adsorption assumption. The hydrophobic interactions are predominant but the selectivity towards phenol, $p$-cresol and even 1-octanol revealed that both the alkyl chains and the H-bonding phenolic group are required to result in efficient exothermic binding with MIPs.

\section{Acknowledgements}

The Equipex Xyloforest program (ANR-10-EQPX-16 XYLOFOREST) is acknowledged for NMR probe funding. P. Stepanek, P. Cernoch and L. Billon coordinators of PHC Barrande (n`38184PB/7AMB17FR032) are sincerely acknowledged for funding E. Decompte’ mobility. This manuscript is in honor of the $50^{\text {th }}$ anniversary of the French Polymer Group (Groupe Français des Polymères - GFP).

Electronic Supporting Information. Proton NMR spectra, number of moles of extracted NP versus centrifugation cycles, monomer conversion versus time plots, Distribution of hydrodynamic diameters of initial liquid miniemulsion, final NIP and MIP particles, derivatization of NP for GC analysis, Calibration curve for GC analysis, Absorbances and UVvisible calibration curves, set up optimal conditions for synthesis of MIP, plots of adsorption capacity versus either water volumic fraction or crosslinker ratio or comonomer, imprinting factor versus crosslinker fraction for 50/50 and 40/60 $\mathrm{H}_{2} \mathrm{O} / \mathrm{EtOH}$ mixtures, ITC titration curves, desorption of NP from MIP in ethanol according to temperature or ultrasonication, FTIR spectra of NIP colloids with various comonomers. 


\section{References}

1. Haupt, K.; Mosbach, K. Molecularly Imprinted Polymers and Their Use in Biomimetic Sensors. Chem. Rev. 2000, 100, 2495-2504.

2. Chen, L.; Wang, X.; Lu, W.; Wu, X.; Li, J. Molecular Imprinting: Perspectives and Applications. Chem. Soc. Rev. 2016, 45, 2137-2211.

3. Pichon, V.; Delaunay, N.; Combes, A. Sample Preparation Using Molecularly Imprinted Polymers. Anal Chem 2020, 92, 16-33.

4. Schwarzenbach, R. P.; Escher, B. I.; Fenner, K.; Hofstetter, T. B.; Johnson, C. A.; von Gunten, U.; Wehrli, B. The Challenge of Micropollutants in Aquatic Systems. Science 2006, 313, 1072-1077.

5. Ribeiro, A. R.; Pedrosa, M.; Moreira, N. F. F.; Pereira, M. F. R.; Silva, A. M. T. Environmental Friendly Method for Urban Wastewater Monitoring of Micropollutants Defined in the Directive 2013/39/Eu and Decision 2015/495/Eu. J. Chromatogr. A 2015, 1418, 140149.

6. Soares, A.; Guieysse, B.; Jefferson, B.; Cartmell, E.; Lester, J. N. Nonylphenol in the Environment: A Critical Review on Occurrence, Fate, Toxicity and Treatment in Wastewaters. Environ Int 2008, 34, 1033-49.

7. Beppu, M.; Nakadai, Y.; Igarashi, Y. Apoptosis Inducing and Enhancing Activities of Environmental Estrogenic Compounds. J. Health Sci. 2006, 52, 831-837.

8. Atienzar, F. A.; Billinghurst, Z.; Depledge, M. H. 4-N-Nonylphenol and 17-B Estradiol May Induce Common DNA Effects in Developing Barnacle Larvae. Environmental Pollution 2002, 120, 735-738.

9. Croce, V.; Patrolecco, L.; Polesello, S.; Valsecchi, S. Extraction of Nonylphenol and Nonylphenol Ethoxylates from River Sediments: Comparison of Different Extraction Techniques. Chromatographia 2003, 58, 145-149.

10. He, C.; Long, Y.; Pan, J.; Li, K.; Liu, F. Application of Molecularly Imprinted Polymers to Solid-Phase Extraction of Analytes from Real Samples. J. Biochem. Bioph. Methods 2007, 70, 133-50.

11. Guerreiro, A.; Soares, A.; Piletska, E.; Mattiasson, B.; Piletsky, S. Preliminary Evaluation of New Polymer Matrix for Solid-Phase Extraction of Nonylphenol from Water Samples. Anal Chim Acta 2008, 612, 99-104.

12. Wulff, G. Molecular Imprinting in Cross-Linked Materials with the Aid of Molecular Templates- a Way Towards Artificial Antibodies. Angew. Chem. Int. Ed. 1995, 34, 18121832.

13. Andersson, L.; Sellergren, B.; Mosbach, K. Imprinting of Amino Acid Derivatives in Macroporous Polymers. Tetrahedron Lett. 1984, 25, 5211-5214.

14. Arshady, R.; Mosbach, K. Synthesis of Substrate-Selective Polymers by Host-Guest Polymerization. Makromol. Chem. 1981, 182, 687-692.

15. Mier, A.; Nestora, S.; Medina Rangel, P. X.; Rossez, Y.; Haupt, K.; Tse Sum Bui, B. Cytocompatibility of Molecularly Imprinted Polymers for Deodorants: Evaluation on Human Keratinocytes and Axillary-Hosted Bacteria. ACS Applied Bio Materials 2019, 2, 3439-3447.

16. Rangel, P. X. M.; Moroni, E.; Merlier, F.; Gheber, L. A.; Vago, R.; Bui, B. T. S.; Haupt, K. Chemical Antibody Mimics Inhibit Cadherin-Mediated Cell-Cell Adhesion: A Promising Strategy for Cancer Therapy. Angew. Chem. Int. Ed. 2020, 59, 2816-2822.

17. Zhou, T. Y.; Ding, L.; Che, G. B.; Jiang, W.; Sang, L. Recent Advances and Trends of Molecularly Imprinted Polymers for Specific Recognition in Aqueous Matrix: Preparation and Application in Sample Pretreatment. Trac-Trends Anal. Chem. 2019, 114, 11-28.

18. Kempe, H.; Kempe, M. Development and Evaluation of Spherical Molecularly Imprinted Polymer Beads. Anal. Chem. 2006, 78, 3659-3666. 
19. Pardeshi, S.; Singh, S. K. Precipitation Polymerization: A Versatile Tool for Preparing Molecularly Imprinted Polymer Beads for Chromatography Applications. RSC Advances 2016, 6, 23525-23536.

20. Zhang, H. Water-Compatible Molecularly Imprinted Polymers: Promising Synthetic Substitutes for Biological Receptors. Polymer 2014, 55, 699-714.

21. Dvorakova, G.; Haschick, R.; Chiad, K.; Klapper, M.; Mullen, K.; Biffis, A. Molecularly Imprinted Nanospheres by Nonaqueous Emulsion Polymerization. Macromol. Rapid Commun. 2010, 31, 2035-2040.

22. Yoshimatsu, K.; Reimhult, K.; Krozer, A.; Mosbach, K.; Sode, K.; Ye, L. Uniform Molecularly Imprinted Microspheres and Nanoparticles Prepared by Precipitation Polymerization: The Control of Particle Size Suitable for Different Analytical Applications. Anal Chim Acta 2007, 584, 112-21.

23. Huang, J.; Tong, J.; Luo, J.; Zhu, Y.; Gu, Y.; Liu, X. Green Synthesis of WaterCompatible Fluorescent Molecularly Imprinted Polymeric Nanoparticles for Efficient Detection of Paracetamol. ACS Sustainable Chem. Eng. 2018, 6, 9760-9770.

24. van Herk, A.; Gilbert, B., Emulsion Polymerisation. Blackwell Science Publ: Oxford, 2005; p 46-78.

25. Landfester, K. Polyreactions in Miniemulsions. Macromol. Rapid Commun. 2001, 22, 896-936.

26. Diltemiz, S. E.; Uslu, O. A Reflectometric Interferometric Nanosensor for Sarcosine. Biotechnol Prog 2015, 31, 55-61.

27. Esfandyari-Manesh, M.; Javanbakht, M.; Dinarvand, R.; Atyabi, F. Molecularly Imprinted Nanoparticles Prepared by Miniemulsion Polymerization as Selective Receptors and New Carriers for the Sustained Release of Carbamazepine. J Mater Sci Mater Med 2012, 23, 963-72.

28. Kara, M.; Uzun, L.; Kolayli, S.; Denizli, A. Combining Molecular Imprinted Nanoparticles with Surface Plasmon Resonance Nanosensor for Chloramphenicol Detection in Honey. J. Appl. Polym. Sci. 2013, 129, 2273-2279.

29. Pourfarzib, M.; Shekarchi, M.; Rastegar, H.; Akbari-Adergani, B.; Mehramizi, A.; Dinarvand, R. Molecularly Imprinted Nanoparticles Prepared by Miniemulsion Polymerization as a Sorbent for Selective Extraction and Purification of Efavirenz from Human Serum and Urine. J. Chromatogr. B Analyt. Technol. Biomed. Life Sci. 2015, 974, 1-8.

30. Corman, M. E.; Armutcu, C.; Uzun, L.; Say, R.; Denizli, A. Self-Oriented Nanoparticles for Site-Selective Immunoglobulin G Recognition Via Epitope Imprinting Approach. Colloids Surf., B 2014, 123, 831-7.

31. Kellens, E.; Bové, H.; Conradi, M.; D’Olieslaeger, L.; Wagner, P.; Landfester, K.; Junkers, T.; Ethirajan, A. Improved Molecular Imprinting Based on Colloidal Particles Made from Miniemulsion: A Case Study on Testosterone and Its Structural Analogues. Macromolecules 2016, 49, 2559-2567.

32. Pluhar, B.; Ziener, U.; Mizaikoff, B. Binding Performance of Pepsin Surface-Imprinted Polymer Particles in Protein Mixtures. J. Mater. Chem.B 2015, 3, 6248-6254.

33. Tan, C. J.; Tong, Y. W. The Effect of Protein Structural Conformation on Nanoparticle Molecular Imprinting of Ribonuclease a Using Miniemulsion Polymerization. Langmuir 2007, 23, 2722-2730.

34. Zhang, N.; Hu, X.; Guan, P.; Du, C.; Li, J.; Qian, L.; Zhang, X.; Ding, S.; Li, B. Preparation of Protein Imprinted Microspheres Using Amphiphilic Ionic Liquid as Stabilizer and Emulsifier Via Miniemulsion Polymerization. Chem. Eng. J. 2017, 317, 356-367.

35. Li-Li, Z.; Yu-Hua, C.; Guang-Qun, C. Preparation and Application of Core-Shell Magnetic Imprinted Nanoparticles for Bisphenol A. Chin. J. Anal. Chem. 2013, 41, 1724-1728. 
36. Shaabani, A.; Afshari, R.; Hooshmand, S. E.; Keramati Nejad, M. Molecularly Imprinted Polymer as an Eco-Compatible Nanoreactor in Multicomponent Reactions: A Remarkable Synergy for Expedient Access to Highly Substituted Imidazoles. ACS Sustainable Chem. Eng. 2017, 5, 9506-9516.

37. Nunez, L.; Turiel, E.; Martin-Esteban, A.; Tadeo, J. L. Molecularly Imprinted Polymer for Selective Extraction of Endocrine Disrupters Nonylphenol and Its Ethoxylated Derivates from Environmental Solids. J. Sep. Sci. 2008, 31, 2492-2499.

38. Anandan, S.; Ashokkumar, M. Sonochemical Synthesis of Au-Tio2 Nanoparticles for the Sonophotocatalytic Degradation of Organic Pollutants in Aqueous Environment. Ultrason. Sonochem. 2009, 16, 316-320.

39. Le Noir, M.; Plieva, F. M.; Mattiasson, B. Removal of Endocrine-Disrupting Compounds from Water Using Macroporous Molecularly Imprinted Cryogels in a Moving-Bed Reactor. J Sep Sci 2009, 32, 1471-9.

40. Huang, J.; Zhang, X.; Liu, S.; Lin, Q.; He, X.; Xing, X.; Lian, W.; Tang, D. Development of Molecularly Imprinted Electrochemical Sensor with Titanium Oxide and Gold Nanomaterials Enhanced Technique for Determination of 4-Nonylphenol. Sens. Actuators, B 2011, 152, 292-298.

41. Bi, Y. J.; Li, W. Y.; Yuan, C.; Wang, B. S. Synthesis of Molecularly Imprinted Polymers for the Binding and Recognition of Nonylphenol. Adv. Mater. Res. 2013, 641-642, 55-59.

42. Chen, H. J.; Zhang, Z. H.; Cai, R.; Chen, X.; Liu, Y. N.; Rao, W.; Yao, S. Z. Molecularly Imprinted Electrochemical Sensor Based on Amine Group Modified Graphene Covalently Linked Electrode for 4-Nonylphenol Detection. Talanta 2013, 115, 222-7.

43. Pan, J.; Li, L.; Hang, H.; Ou, H.; Zhang, L.; Yan, Y.; Shi, W. Study on the Nonylphenol Removal from Aqueous Solution Using Magnetic Molecularly Imprinted Polymers Based on Fly-Ash-Cenospheres. Chem. Eng. J. 2013, 223, 824-832.

44. Han, S.; Li, X.; Wang, Y.; Su, C. A Core-Shell Fe3o4 Nanoparticle-Cdte Quantum DotMolecularly Imprinted Polymer Composite for Recognition and Separation of 4-Nonylphenol. Anal. Methods 2014, 6, 2855-2861.

45. Rao, W.; Cai, R.; Yin, Y.; Long, F.; Zhang, Z. Magnetic Dummy Molecularly Imprinted Polymers Based on Multi-Walled Carbon Nanotubes for Rapid Selective Solid-Phase Extraction of 4-Nonylphenol in Aqueous Samples. Talanta 2014, 128, 170-176.

46. Chen, F.-Y.; Ba, S.-P.; Tang, Y.-B.; Wang, X.-G. Preparation and Characterization of Nonylphenol Magnetic Molecularly Imprinted Polymer. J. Chem. Soc. Pak. 2015, 37, $1143-$ 1152.

47. Pan, Y.; Shang, L.; Zhao, F.; Zeng, B. A Novel Electrochemical 4-Nonyl-Phenol Sensor Based on Molecularly Imprinted Poly (O-Phenylenediamine-Co-O-Toluidine)-NitrogenDoped Graphene Nanoribbons-Ionic Liquid Composite Film. Electrochim. Acta 2015, 151, 423-428.

48. Huang, L.; Zhai, H.; Liang, G.; Su, Z.; Yuan, K.; Lu, G.; Pan, Y. Chip-Based DualMolecularly Imprinted Monolithic Capillary Array Columns Coated Ag/Go for Selective Extraction and Simultaneous Determination of Bisphenol a and Nonyl Phenol in Fish Samples. J. Chromatogr. A 2016, 1474, 14-22.

49. Ai, J.; Guo, H.; Xue, R.; Wang, X.; Lei, X.; Yang, W. A Self-Probing, Gate-Controlled, Molecularly Imprinted Electrochemical Sensor for Ultrasensitive Determination of PNonylphenol. Electrochem. Commun. 2018, 89, 1-5.

50. Zheng, L.; Zhang, C.; Ma, J.; Hong, S.; She, Y.; Abd El-Aty, A. M.; Yahui, H.; Yu, H.; Liu, H.; Wang, J. Fabrication of a Highly Sensitive Electrochemical Sensor Based on Electropolymerized Molecularly Imprinted Polymer Hybrid Nanocomposites for the Determination of 4-Nonylphenol in Packaged Milk Samples. Anal. Biochem. 2018, 559, 44-50. 
51. Xie, X.; Ma, X.; Guo, L.; Fan, Y.; Zeng, G.; Zhang, M.; Li, J. Novel Magnetic MultiTemplates Molecularly Imprinted Polymer for Selective and Rapid Removal and Detection of Alkylphenols in Water. Chem. Eng. J. 2019, 357, 56-65.

52. Liu, J.; Debuigne, A.; Detrembleur, C.; Jerome, C. Poly(N-Vinylcaprolactam): A Thermoresponsive Macromolecule with Promising Future in Biomedical Field. Adv. Healthcare Mater. 2014, 3, 1941-68.

53. Vihola, H.; Laukkanen, A.; Tenhu, H.; Hirvonen, J. Drug Release Characteristics of Physically Cross-Linked Thermosensitive Poly(N-Vinylcaprolactam) Hydrogel Particles. $J$. Pharm. Sci. 2008, 97, 4783-93.

54. Gaballa, H. A.; Geever, L. M.; Killion, J. A.; Higginbotham, C. L. Synthesis and Characterization of Physically Crosslinked N-Vinylcaprolactam, Acrylic Acid, Methacrylic Acid and N,N-Dimethylacrylamide Hydrogels. J. Polym. Sci., Part B: Polym. Phys. 2013, 51, $1555-1564$.

55. Popescu, I.; Suflet, D. M.; Pelin, I. M. Investigation of Interpolymer Complexation between Poly(Vinylcaprolactam) and Poly(Maleic Acid-Alt-Styrene). J. Macromol. Sci., Part B: Phys. 2016, 55, 708-721.

56. Kozlovskaya, V.; Liu, F.; Xue, B.; Ahmad, F.; Alford, A.; Saeed, M.; Kharlampieva, E. Polyphenolic Polymersomes of Temperature-Sensitive Poly(N-Vinylcaprolactam)-BlockPoly(N-Vinylpyrrolidone) for Anticancer Therapy. Biomacromolecules 2017, 18, 2552-2563. 57. Gomar, M.; Panahi, H. A.; Pournamdari, E. Synthesis and Characterization of Thermosensitive Molecularly Imprinted Poly[Allylacetoacetate/N-Vinyl Caprolactam] for Selective Extraction of Gemcitabine in Biological Samples. ChemistrySelect 2018, 3, 25712577.

58. Sajadi, P.; Panahi, H. A.; Azarakhshi, F. Selective Extraction and Determination of Sumatriptan Succinate in Human Urine by Synthesized Thermosensitive Molecularly Imprinted Poly(3-Allyloxy-1, 2-Propanediol/N-Vinylcaprolactam). Sep. Sci. Technol. 2018, 53, 29062915.

59. Zuber, S.; Landfester, K.; Crespy, D.; Popa, A. M. Temperature Responsive Copolymers of N-Vinylcaprolactam and Di(Ethylene Glycol) Methyl Ether Methacrylate and Their Interactions with Drugs. J. Polym. Sci., Part A: Polym. Chem. 2013, 51, 3308-3313.

60. Kehren, D.; Lopez, C. M.; Theiler, S.; Keul, H.; Möller, M.; Pich, A. Multicompartment Aqueous Microgels with Degradable Hydrophobic Domains. Polymer 2019, 172, 283-293.

61. Petrizza, L.; Le Bechec, M.; Decompte, E.; El Hadri, H.; Lacombe, S.; Save, M. Tuning Photosensitized Singlet Oxygen Production from Microgels Synthesized by Polymerization in Aqueous Dispersed Media. Polym. Chem. 2019, 10, 3170-3179.

62. Brix, R.; Hvidt, S.; Carlsen, L. Solubility of Nonylphenol and Nonylphenol Ethoxylates, on the Possible Role of Micelles. Chemosphere 2001, 44, 759-763.

63. Cavalheiro, J.; Monperrus, M.; Amouroux, D.; Preud'Homme, H.; Prieto, A.; Zuloaga, O. In-Port Derivatization Coupled to Different Extraction Techniques for the Determination of Alkylphenols in Environmental Water Samples. J. Chromatogr. A 2014, 1340, 1-7.

64. Zhen, Y.; Ning, Z.; Shaopeng, Z.; Yayi, D.; Xuntong, Z.; Jiachun, S.; Weiben, Y.; Yuping, W.; Jianqiang, C. A Ph- and Temperature-Responsive Magnetic Composite Adsorbent for Targeted Removal of Nonylphenol. ACS Appl. Mater. Interfaces 2015, 7, 24446-24457.

65. Ekomo, V. M.; Branger, C.; Bikanga, R.; Florea, A. M.; Istamboulie, G.; CalasBlanchard, C.; Noguer, T.; Sarbu, A.; Brisset, H. Detection of Bisphenol a in Aqueous Medium by Screen Printed Carbon Electrodes Incorporating Electrochemical Molecularly Imprinted Polymers. Biosens. Bioelectron. 2018, 112, 156-161.

66. Imaz, A.; Miranda, J. I.; Ramos, J.; Forcada, J. Evidences of a Hydrolysis Process in the Synthesis of N-Vinylcaprolactam-Based Microgels. Eur. Polym. J. 2008, 44, 4002-4011. 
67. Etchenausia, L.; Deniau, E.; Brûlet, A.; Forcada, J.; Save, M. Cationic Thermoresponsive Poly(N-Vinylcaprolactam) Microgels Synthesized by Emulsion Polymerization Using a Reactive Cationic Macro-Raft Agent. Macromolecules 2018, 51, 25512563.

68. Cavalheiro, J.; Preud'Homme, H.; Amouroux, D.; Tessier, E.; Monperrus, M. Comparison between Gc-Ms and Gc-Icpms Using Isotope Dilution for the Simultaneous Monitoring of Inorganic and Methyl Mercury, Butyl and Phenyl Tin Compounds in Biological Tissues. Anal. Bioanal. Chem. 2014, 406, 1253-1258.

69. Etchenausia, L.; Rodrigues, A. M.; Harrisson, S.; Deniau Lejeune, E.; Save, M. Raft Copolymerization of Vinyl Acetate and N-Vinylcaprolactam: Kinetics, Control, Copolymer Composition, and Thermoresponsive Self-Assembly. Macromolecules 2016, 49, 6799-6809.

70. Dossot, M.; Sylla, M.; Allonas, X.; Merlin, A.; Jacques, P.; Fouassier, J. P. Role of Phenolic Derivatives in Photopolymerization of an Acrylate Coating. J. Appl. Polym. Sci. 2000, 78, 2061-2074.

71. Reichardt, C., In Solvents and Solvent Effects in Organic Chemistry, Third Edition, 2003 Wiley-VCH Verlag GmbH \& Co. KGaA 2003.

72. Sanbe, H.; Hosoya, K.; Haginaka, J. Preparation of Uniformly Sized Molecularly Imprinted Polymers for Phenolic Compounds and Their Application to the Assay of Bisphenol a in River Water. Anal. Sci. 2003, 19, 715-719.

73. Hansch, C.; Leo, A.; Hoekman, D., Exploring Qsar. [2] Hydrophobic, Electronic, and Steric Constants, Acs Professional Reference Book. American Chemical Society: Washington (DC, USA), 1995.

74. Langmuir, I. The Constitution and Fundamental Properties of Solids and Liquids. Part I Solids. J. Am. Chem. Soc. 1916, 38, 2221-2295.

75. Freundlich, H. Over the Adsorption in Solution. J. Phys. Chem. A 1906, 57, 385-471.

76. Yu, P.; Sun, Q.; Li, J.; Tan, Z.; Yan, Y.; Li, C. Magnetic Imprinted Nanomicrosphere Attached to the Surface of Bacillus Using Miniemulsion Polymerization for Selective Recognition of 2,4,6-Trichlorophenol from Aqueous Solutions. J. Ind. Eng. Chem. 2015, 29, 349-358.

77. Weber, T. W.; Chakravorti, R. K. Pore and Solid Diffusion Models for Fixed-Bed Adsorbers. AlChE J. 1974, 20, 228-238.

78. Scatchard, G. The Attractions of Proteins for Small Molecules and Ions. Ann. N.Y. Acad. Sci. 1949, 51, 660-672.

79. Bedwell, T. S.; Whitcombe, M. J. Analytical Applications of Mips in Diagnostic Assays: Future Perspectives. Anal Bioanal Chem 2016, 408, 1735-51.

80. Abdul-quadir, M. S.; van der Westhuizen, R.; Welthagen, W.; Ferg, E. E.; Tshentu, Z. R.; Ogunlaja, A. S. Adsorptive Denitrogenation of Fuel over Molecularly Imprinted Poly-2(1h-Imidazol-2-Y1)-4-Phenol Microspheres. New J. Chem. 2018, 42, 13135-13146.

81. Liu, T.; Xie, Z.; Zhang, Y.; Fan, J.; Liu, Q. Preparation of Cationic Polymeric Nanoparticles as an Effective Adsorbent for Removing Diclofenac Sodium from Water. RSC Advances 2017, 7, 38279-38286.

82. Zhang, Z.; Liu, J. Molecularly Imprinted Polymers with DNA Aptamer Fragments as Macromonomers. ACS Appl. Mater. Interfaces 2016, 8, 6371-6378.

83. Zhang, Z. J.; Liu, J. W. Improving Molecularly Imprinted Nanogels by Ph Modulation. RSC Advances 2015, 5, 91018-91025. 